OPEN ACCESS

Edited by:

Marcin Okrój,

University of Gdańsk and Medical

University of Gdańsk, Poland

Reviewed by:

Christoph Q. Schmidt,

University of UIm, Germany

Lubka T. Roumenina,

INSERM U1138 Centre de Recherche

des Cordeliers (CRC), France

*Correspondence:

B. Paul Morgan

morganbp@cardiff.ac.uk

Wioleta M. Zelek

zelekw@cardiff.ac.uk

Specialty section:

This article was submitted to

Molecular Innate Immunity,

a section of the journal

Frontiers in Immunology

Received: 30 September 2020

Accepted: 09 November 2020

Published: 10 December 2020

Citation:

Zelek WM and Morgan BP (2020)

Monoclonal Antibodies Capable of Inhibiting Complement Downstream of

C5 in Multiple Species.

Front. Immunol. 11:612402.

doi: 10.3389/fimmu.2020.612402

\section{Monoclonal Antibodies Capable of Inhibiting Complement Downstream of C5 in Multiple Species}

\author{
Wioleta M. Zelek * and B. Paul Morgan * \\ Systems Immunity Research Institute, Division of Infection and Immunity and Dementia Research Institute, School of \\ Medicine, Cardiff University, Wales, United Kingdom
}

Better understanding of roles of complement in pathology has fuelled an explosion of interest in complement-targeted therapeutics. The C5-blocking monoclonal antibody (mAb) eculizumab, the first of the new wave of complement blocking drugs, was FDA approved for treatment of Paroxysmal Nocturnal Hemoglobinuria in 2007; its expansion into other diseases has been slow and remains restricted to rare and ultra-rare diseases such as atypical hemolytic uremic syndrome. The success of eculizumab has provoked other Pharma to follow this well-trodden track and made C5 blockade the busiest area of complement drug development. C5 blockade inhibits generation of C5a and C5b, the former an anaphylatoxin, the latter the nidus for formation of the pro-inflammatory membrane attack complex. In order to use anti-complement drugs in common complement-driven diseases, more affordable and equally effective therapeutics are needed. To address this, we explored complement inhibition downstream of C5. Novel blocking mAbs targeting $\mathrm{C} 7$ and/or the C5b-7 complex were generated, identified using high throughput functional assays and specificity confirmed by immunochemical assays and surface plasmon resonance (SPR). Selected mAbs were tested in rodents to characterize pharmacokinetics, and therapeutic capacity. Administration of a mouse C7-selective mAb to wildtype mice, or a human C7 specific mAb to C7-deficient mice reconstituted with human $\mathrm{C} 7$, completely inhibited serum lytic activity for $>48 \mathrm{~h}$. The $\mathrm{C} 5 \mathrm{~b}-$ 7 complex selective mAb $2 \mathrm{H} 2$, most active in rat serum, efficiently inhibited serum lytic activity in vivo for over a week from a single low dose (10 mg/kg); this mAb effectively blocked disease and protected muscle endplates from destruction in a rat myasthenia model. Targeting C7 and C7-containing terminal pathway intermediates is an innovative therapeutic approach, allowing lower drug dose and lower product cost, that will facilitate the expansion of complement therapeutics to common diseases. 


\section{INTRODUCTION}

The complement system comprises over 50 proteins, regulators and receptors circulating in plasma or on cells. Activation of the system by three distinct pathways, classical, lectin, and alternative, the latter comprising a common amplification loop, leads to formation of C 3 convertases, followed by $\mathrm{C} 5$ convertases which cleave $\mathrm{C} 5$ into the potent chemotactic anaphylatoxin $\mathrm{C} 5 \mathrm{a}$, and $\mathrm{C} 5 \mathrm{~b}$, the nidus for formation of the cytotoxic proinflammatory membrane attack complex (MAC). C5b while associated with the convertase, sequentially binds the plasma proteins $\mathrm{C} 6$ and $\mathrm{C}$, generating the C5b-7 complex that undergoes conformational change, triggering release from the convertase and exposing a labile hydrophobic membrane binding surface. The C5b-7 complex through its hydrophobic surface tightly binds membrane and sequentially recruits $\mathrm{C} 8$ and $\mathrm{C} 9$ to create the MAC, a transmembrane pore comprising one molecule each of $\mathrm{C} 5 \mathrm{~b}, \mathrm{C} 6$, $\mathrm{C} 7$, and $\mathrm{C} 8$ and up to 18 copies of $\mathrm{C} 9$ that are recruited sequentially. The MAC pore allows metabolites and small proteins to leak out of the cell and water to flood into the cell due to osmotic pressure leading to lytic cell death (1-3).

Complement is critical to immune defense, providing recognition, tagging and elimination of bacteria and other foreign intruders and immune complexes; however, inappropriate activation of the system can lead to self-tissue and self-cell damage, driving disease. Hence, there is a need for therapies that block complement. For more than a decade, there was only one anti-complement drug in the clinic, the anti-C5 monoclonal antibody (mAb) eculizumab; this drug was FDA approved in 2007 for the ultra-rare hemolytic disease paroxysmal nocturnal hemoglobinuria (PNH), in 2011 for the ultra-rare renal disease atypical hemolytic uremic syndrome (aHUS), and for myasthenia gravis (MG) therapy in 2017 and in 2019 for the treatment of anti-aquaporin-4 (AQP4) antibody positive neuromyelitis optica spectrum disorder (NMOSD) in adults (1). At a list price of approximately $\$ 500,000$ per patient per year, eculizumab, remains one of the most expensive therapies in the world. The drug must be given bi-weekly by intravenous infusion, 0.9 to $1.2 \mathrm{~g} /$ dose $(1-5)$. These factors restrict progress toward therapy of more common complement-driven diseases. A step change is now needed to enable the use of anti-complement drugs in these conditions where there is considerable unmet need and many patients do not respond adequately to currently available agents. Anti-complement drugs for common conditions must be safer, cheaper and easier to administer.

Although the complement cascade can be targeted at many stages, anti-complement drugs in development are focused on very few targets, with agents mimicking eculizumab and targeting $\mathrm{C} 5$ or its breakdown products predominating. This is at least in part because inhibition of $\mathrm{C} 5$ has proven to be relatively low risk; the increased risk of Neisserial infections is managed by vaccination before treatment and prophylactic use of antibiotics. There are numerous agents in development that target C5, for example, crovalimab (SKY59), a C5 blocking mAb utilizing a $\mathrm{pH}$-dependent recycling technology to increase drug half-life, and reduce the dose required to block C5 (in phase III clinical trials; $(1,6) \mathrm{https} / / /$ clinicaltrials.gov/ct2/show/
NCT04432584), and ravulizumab, the "next generation" eculizumab that also incorporates recycling technology enabling an increase in dosing interval to eight weeks. Ravulizumab has been FDA approved for PNH (2018) and aHUS (2019) (7).

Currently, only one drug targeting MAC downstream of $\mathrm{C} 5$ has progressed to clinical trials; AAVCAGsCD59 is a gene therapy agent in development for age-related macular degeneration (AMD); the agent is injected into the eye to locally express a non-anchored form of the MAC inhibitor CD59 (8). An anti-C6 mAb (CP010), developed by Complement Pharma and now partnered with Alexion, is in pre-clinical testing. (https://globalgenes.org/2018/06/ 12/alexion-and-complement-pharma-form-partnership-to-codevelop-complement-inhibitor-for-neurodegenerative-disorders/). In the wider literature there are a few preclinical reports describing targeting MAC beyond $\mathrm{C} 5$. An anti-C8 $\mathrm{mAb}$ was tested in hyperacute rejection (HAR) and cardiopulmonary bypass $(\mathrm{CPB})$ rodent models; $(9,10)$ in HAR, mAb treatment protected hearts perfused with human serum while in $\mathrm{CPB}$ the $\mathrm{mAb}$ reduced platelet activation. A polyclonal antibody against C6 inhibited clinical symptoms in an experimental MG (EAMG) model in rats (11). Neither of these agents was advanced further. A very recent report described a monoclonal anti-C6 that inhibited hemolysis in human and rhesus monkey serum (12). These reports not only highlight the therapeutic potential of developing anti-terminal pathway drugs beyond $\mathrm{C} 5$, but also demonstrate the crucial role of MAC as a pathology driver.

Here we describe a panel of terminal pathway blocking $\mathrm{mAbs}$, generated in C7-knockout (KO) mice hyper-immunized with human or rat C5b-7 and/or C7. The selected anti-human mAbs were equivalent or better inhibitors of human complement when compared to eculizumab in standard activity assays. Some of the mAbs showed cross-species activity when tested against human and rodent sera and the relevant mAbs efficiently inhibited complement activity in vivo in rodents. For one $\mathrm{mAb}$, reactive against rat C5b-7, a single low dose inhibited complement for over a week in rats and blocked disease in the rat EAMG model.

\section{MATERIALS AND METHODS}

\section{Reagents and Sera}

All chemicals, except where otherwise stated, were obtained from either Fisher Scientific UK (Loughborough, UK) or Sigma Aldrich (Gillingham, UK) and were of analytical grade. All tissue culture reagents and plastics were from Invitrogen Life Technologies (Paisley, UK). Sheep and guinea pig erythrocytes in Alsever's solution were from TCS Biosciences (Claydon, UK). Eculizumab was kindly donated by Prof. David Kanavagh (Newcastle University, UK), and crovalimab by Roche Diagnostics (Basel, Switzerland). Cynomolgus monkey serum was purchased from Serlab (\#S-118-D-24526, London, UK). Human and animal sera were prepared in house from freshly collected blood. For human, rabbit and rat, blood was clotted at room temperature (RT) for $1 \mathrm{~h}$, then placed on ice for $2 \mathrm{~h}$ for clot retraction before centrifugation and harvesting of serum. For mouse, blood was placed on ice immediately after harvest and clotted for $2 \mathrm{~h}$ on ice 
before serum harvest. Sera were stored in aliquots at $-80^{\circ} \mathrm{C}$ and not subjected to freeze-thaw cycles.

\section{Generation of mAbs}

Monoclonal antibodies against $\mathrm{C} 7 / \mathrm{C} 5 \mathrm{~b}-7$ protein were generated by first establishing a line of $\mathrm{C} 7$ deficient mice. CRISP-generated heterozygous $\mathrm{C} 7 \mathrm{KO}$ mice $\left(\mathrm{C} 57 \mathrm{BL} / 6 \mathrm{NJ}-\mathrm{C}^{\mathrm{em} 1(\mathrm{IMPC}) \mathrm{J}} / \mathrm{Mmjax}\right.$ ) were purchased from Jackson Laboratories (Bar Harbour, Maine, USA) and back-crossed to obtain homozygous C7 deficient mice. The absence of C7 was confirmed by western blotting (WB) and hemolytic assays (data not shown). Wildtype (WT) and $\mathrm{C} 7 \mathrm{KO}$ mice were immunized with rat $\mathrm{C} 7$ and human C7/C5b-7 (both purified in-house) using standard schedules (13). The C7 KO mice were also used as a source of feeder macrophages during the cloning process. Immunized mice were screened using enzyme-linked immunosorbent assay (ELISA), mice with the highest titer response against the immunized proteins were selected and re-boosted before killing and harvesting of spleens. Plasma cells were harvested, fused with SP2 myeloma and aliquoted into 96-well plates. Hybridoma supernatants were screened using high-throughput hemolytic assay (described below) to identify blocking mAbs; supernatants with blocking activity were also screened for antibody responses by ELISA. Complement blocking mAb-secreting clones were sub-cloned by limiting dilution to monoclonality. Mouse mAbs were isotyped using IsoStrips (\# 11493027001; Roche).

\section{Hemolytic Assays}

The capacity of the mAbs to inhibit complement in human and animal sera was investigated by classical pathway (CP; $\mathrm{CH} 50)$ hemolysis assay using antibody-sensitized sheep erythrocytes (ShEA); sheep blood was from TCS Bioscience and anti-ShE antiserum (\#ORLC25, Siemens Amboceptor) was from Cruinn Diagnostics (Dublin, UK). ShEA were suspended in HEPESbuffered saline (HBS) containing $\mathrm{Ca}^{2+}$ and $\mathrm{Mg}^{2+}$ at $2 \%$ (vol:vol) (14). For measurement of activity in male mouse serum, ShEA were additionally incubated with mouse anti-rabbit IgG at $25 \mu \mathrm{g} /$ $\mathrm{ml}$ (\#3123; Invitrogen) for $30 \mathrm{~min}$ at $37^{\circ} \mathrm{C}$ before washing in HBS. A serial dilution series of each test $\mathrm{mAb}(100-0 \mu \mathrm{g} / \mathrm{ml} ; 50$ $\mu \mathrm{l} /$ well) was prepared in HBS and aliquoted in triplicate into a 96-well round-bottomed plate at $50 \mu \mathrm{l} /$ well, then serum and $2 \%$ ShEA ( $50 \mu \mathrm{l} /$ well of each) added. Serum dilutions for each species were selected in preliminary experiments to give near complete hemolysis in the absence of test mAb: 2.5\%: normal human serum (NHS); 10\%: normal Cynomolgus monkey serum (Cyno); $2.5 \%$ normal rat serum (NRS); $25 \%$ : normal rabbit serum (NRbS); 25\%: normal male mouse serum (NMS) (using the double-sensitized cells as described above). Plates were incubated at $37^{\circ} \mathrm{C}$ for $30 \mathrm{~min}$, centrifuged and hemoglobin in the supernatant was measured by absorbance at $405 \mathrm{~nm}$. Percentage lysis was calculated according to: \% Lysis = Absorbance (Abs) sample - Abs background)/(Abs max - Abs background) $\times 100 \%$. GraphPad Prism was used for data analysis. Hybridoma supernatants were screened for blocking mAbs using the same assay but with neat tissue culture supernatant in place of the purified mAb.
Reactive lysis assays were used to identify mechanism of $\mathrm{mAb}$ inhibition. Guinea pig blood was from TCS; erythrocytes (GPE) at $2 \%$ in $\mathrm{HBS}(50 \mu \mathrm{l} /$ well) were incubated sequentially with C5b6, C7, C8 and C9 (in house, affinity purified (15)), each for $10 \mathrm{~min}$ at $37^{\circ} \mathrm{C}$, at doses titrated to give $\sim 75 \%$ to $90 \%$ hemolysis in the absence of inhibitor. The concentrations (per well) of the purified components used were as follow; C5b6; $45 \mathrm{ng} / \mathrm{ml}, \mathrm{C} 7 ; 184 \mathrm{ng} / \mathrm{ml}$, C8; $168 \mathrm{ng} / \mathrm{ml}, \mathrm{C} 9 ; 383 \mathrm{ng} / \mathrm{ml}$. Molarities in nM; C5b6, 0.16; C7, 1.99; C8, 1.11; C9, 5.39 (Ratios: 1: 13: 10: 34). Serial dilutions (in triplicate) of the $\mathrm{mAb}(1-0 \mu \mathrm{g} / \mathrm{ml})$ were made into HBS and added to the wells at different stages of MAC formation to determine the inhibition. Test and control $\mathrm{mAb}$ were added either prior to addition of C7 (human or rat), or prior to addition of $\mathrm{C} 8 / \mathrm{C} 9$ and incubated for $30 \mathrm{~min}$ at $37^{\circ} \mathrm{C}$. In some assay ratEDTA serum was used as source of rat C8 and C9 to develop lysis of C5b-7 (human or rat C7) coated cells. Plates were centrifuged at $2000 \mathrm{rpm}$ for $3 \mathrm{~min}$ at $4^{\circ} \mathrm{C}$, supernatants removed to a flatwelled microtiter plate, absorbances measured spectrophometrically $\left(\mathrm{A}_{405} \mathrm{~nm}\right)$ and \% lysis calculated.

To reduce the need for large volumes of fresh mouse serum, add-back hemolytic assays were used for testing of lytic activity in mice treated with the mAb. NHS depleted of C7 (C7D) or C5 (C5D) was used as source of the rest of the complement proteins; mouse serum was added (1:2 v:v; mouse serum:C7D/C5D) to restore the relevant component. The serum mix was diluted to $10 \%$ in HBS then plated in a dilution series $(50 \mu \mathrm{l} /$ well; $10-0 \%)$ in HBS in a round bottom microwell plate; $50 \mu \mathrm{l} 2 \%$ ShEA and $50 \mu \mathrm{l}$ HBS were added (final concentrations of serum mix in wells: $3.3-$ $0 \%$ ), incubated for $30 \mathrm{~min}$ at $37^{\circ} \mathrm{C}$. Plates were centrifuged, supernatants removed to a flat-welled microtiter plate and absorbance measured spectrophometrically $\left(\mathrm{A}_{405} \mathrm{~nm}\right)$. \% lysis was calculated.

\section{Characterization of Novel mAbs by ELISA and WB}

Direct ELISA was used to test whether the new mAb bound C7 from different species. Sandwich ELISA were used to confirm C7 binders, to eliminate issues around denaturation by protein binding on plastic, and to test whether the mAbs competed for the same binding epitope. Standard curves were generated using in-house human or animal (rat, mouse, monkey) C7 proteins, immunoaffinity purified as previously described (15). In the direct ELISA, Maxisorp (Nunc, Loughborough, UK) 96-well plates were coated with $\mathrm{C} 7(0.5 \mu \mathrm{g} / \mathrm{ml}$ in bicarbonate buffer, $\mathrm{pH} 9.6)$ at $4^{\circ} \mathrm{C}$ overnight; wells were blocked $(1 \mathrm{~h})$ at $37^{\circ} \mathrm{C}$ with $2 \%$ bovine serum albumin (BSA) in phosphate-buffered saline (PBS), washed in PBS containing 0.05\% Tween 20 (PBS-T). Dilutions of purified mAb, 1000-0 ng/ml (stock concentrations of all proteins used established using the BCA assay) in $0.2 \%$ BSA-PBS, were added in triplicate to wells coated with each of the antigens and incubated for $1 \mathrm{~h}$ at $37^{\circ} \mathrm{C}$. Wells were washed with PBS-T then incubated $\left(1 \mathrm{~h}, 37^{\circ} \mathrm{C}\right)$ with secondary antibody (donkey anti-mouse-horseradish peroxidase (HRP); Jackson ImmunoResearch, Ely, UK) for $1 \mathrm{~h}$ at $37^{\circ} \mathrm{C}$. In the sandwich ELISA, Maxisorp plates were coated with $\mathrm{mAb}(2 \mu \mathrm{g} / \mathrm{ml}$ in bicarbonate buffer, $\mathrm{pH} 96)$ at $4^{\circ} \mathrm{C}$ overnight; wells were 
blocked ( $1 \mathrm{~h}$ at $37^{\circ} \mathrm{C}$ with $2 \%$ BSA-PBS) and washed in PBS-T. Standard curves were generated using in-house purified C7 protein serially diluted in $0.2 \%$ BSA-PBS, added in triplicate and incubated for $1 \mathrm{~h}$ at $37^{\circ} \mathrm{C}$. Wells were washed with PBS-T then incubated $\left(1 \mathrm{~h}, 37^{\circ} \mathrm{C}\right)$ with the paired HRP-labeled $\mathrm{mAb}$ ( 1 in 1000 dilution in PBS-T; Pierce, \#31489). After washing, plates were developed using O-phenylenediamine dihydrochloride (OPD, Sigma FAST ${ }^{\mathrm{TM}}$; Sigma-Aldrich) and absorbance (492 $\mathrm{nm}$ ) was measured. GraphPad Prism was used for data analysis.

To confirm specificity for $\mathrm{C} 7$ and the species reactivity, C7 protein (in house; $0.5 \mu \mathrm{g}$ ) or human or animal (mouse, rat, monkey) sera diluted 1:100 in PBS were placed in separate wells and resolved on 4-20\% sodium dodecyl sulphate-polyacrylamide gel (SDS-PAGE) electrophoresis gels (\#4561093; Biorad, Hemel Hempstead, UK) under reducing (R) and non-reducing (NR) conditions, then electrophoretically transferred onto $0.45 \mu \mathrm{m}$ nitrocellulose membrane (GE Healthcare, Amersham, UK). After transfer, non-specific sites on the membrane were blocked with 5\% BSA in PBS-T. After washing in PBS-T, membrane strips were incubated overnight at $4^{\circ} \mathrm{C}$ with individual test $\mathrm{mAb}$ (each at $1 \mu \mathrm{g} / \mathrm{ml}$ in 5\% BSA PBS-T) or polyclonal (goat) anti-human C7 $(2 \mu \mathrm{g} / \mathrm{ml}$, CompTech, Tyler, TX; A224). After washing, bound test $\mathrm{mAb}$ were detected by incubation with donkey anti-mouse IgGHRP (\#715-035-150, Jackson ImmunoResearch) and polyclonal anti-C7 with rabbit anti-goat IgG HRP conjugate (\#305-035-045; Jackson ImmunoResearch) at 1: 10000 in 5\% BSA PBS-T. Blots were washed, developed with enhanced chemiluminescence (GE Healthcare) and visualized by autoradiography.

To characterize mAb binding to soluble terminal complement complexes (TCC), biotinylated mAbs (Pierce, \#21327) were individually added to human or rat serum $(100 \mu \mathrm{g} / \mathrm{ml}$ in $3 \mathrm{ml}$ serum) and the mix activated via both classical and alternative pathways by incubation with Zymosan A (7 mg/ml; \#21327, Pierce) and aggregated human IgG ( $1 \mathrm{mg} / \mathrm{ml}$; in house) for $32 \mathrm{~h}$ at $37^{\circ} \mathrm{C}$ in a shaking water bath. The reaction was stopped by centrifugation at $2500 \mathrm{rpm}$ for $15 \mathrm{~min}$ at $4^{\circ} \mathrm{C}$ and the supernatant (activated serum) collected. For analysis by WB, supernatant was mixed with $0.25 \mathrm{ml}$ Avidin-coated beads (prepared by coupling avidin to HiTrap N-hydroxysuccinimide-activated beads; \#170716-01, GE Healthcare, Little Chalfont, UK). The mixture was incubated for 1 hat RT while mixing gently, the beads washed five times in PBS by centrifugation (1000 rpm for $1 \mathrm{~min}$ ) and the bound $\mathrm{mAb}$-complex eluted by incubation $\left(10 \mathrm{~min}\right.$ at $\left.100^{\circ} \mathrm{C}\right)$ in reducing or non-reducing SDS-PAGE running buffer. Supernatants were subjected to SDS-PAGE and WB as above. Blots were blocked with 5\% BSA, washed, cut into strips and individual strips incubated with goat anti-C5, -C6, -C7, -C8 or -C9 antibodies (at $2 \mu \mathrm{g} / \mathrm{ml}$, Comptech, Tyler, TX; A220, 223, 224, $225,226)$ for $1 \mathrm{~h}$, washed then incubated with horseradish peroxidase HRP-conjugated anti-goat immunoglobulin (1: 10 000 dilutions, \#305-035-045; Jackson ImmunoResearch) for $1 \mathrm{~h}$ at RT with constant mixing. After washing, blots were developed as described above. For analysis by ELISA, supernatant was added to 96-well plates coated with Avidin $(10 \mu \mathrm{g} / \mathrm{ml})$, incubated $1 \mathrm{~h}$ at $37^{\circ} \mathrm{C}$ and blocked with $2 \%$ BSA $\left(1 \mathrm{~h}\right.$ at $\left.37^{\circ} \mathrm{C}\right)$; after washing, terminal pathway components in the pull-down samples were detected with Goat anti-C5, C6, C7, C8 or C9 antibodies as above at $2 \mu \mathrm{g} / \mathrm{ml}$ diluted in $0.2 \%$ BSA PBS-T then developed with rabbit anti-Goat-HRP, \#305-035-045; Jackson ImmunoResearch). Controls for each antibody comprised biotinylated $\mathrm{mAb}$ alone or incubated with $\mathrm{C} 7$. The assay was developed as described above.

Binding of the mAbs to pre-formed TCC was tested in ELISA; serum activated as above in the absence of mAbs ( 1 in 50 dilution in $0.2 \%$ BSA-PBS-T) was transferred to plates coated with aE11 anti-C9 neo-specific antibody $(5 \mu \mathrm{g} / \mathrm{ml}$, Hycult Biotech, \# HM2167), incubated $1 \mathrm{~h}$ at $37^{\circ} \mathrm{C}$ and blocked with $2 \%$ BSA $\left(1 \mathrm{~h}\right.$ at $\left.37^{\circ} \mathrm{C}\right)$; after washing, the new biotinylated $\mathrm{mAb}$ or as positive control, an in house $\mathrm{mAb}$ known to bind aE11-captured TCC (E2 anti-C8; 1 in 1000 dilution in 0.2\% BSA-PBS-T) were added and incubated for $1 \mathrm{~h}$ at $37^{\circ} \mathrm{C}$, after washing, StreptavidinHRP ( 1 in 5000 dilution in $0.2 \%$ BSA-PBS-T, Fisher Scientific, \# 21130) was added, plates incubated $1 \mathrm{~h}$ at $37^{\circ} \mathrm{C}$ and the assay developed as described above.

\section{SPR Analysis to Determine Test mAbs Binding Affinity to Human C7}

The mAbs binding analyses were carried out on a Biacore T200 instrument (GE Healthcare); for $\mathrm{mAb}$ of isotype $\mathrm{IgG}$, an antibody capture kit (GE Healthcare, \# BR-1008-38) was used to immobilize the $\mathrm{mAb}$ on a CM5 sensor chip (GE Healthcare, $\# 29-1496-03)$ as recommended by the manufacturer. mAb isotype $\operatorname{IgM}$ was immobilized on a Protein L Series S sensor chip (GE Healthcare \#29-2051-38). mAb were flowed to saturate the surface, then $\mathrm{C7}$, human, rat or mouse, diluted in EP-HBS (10 mM HEPES, pH 7.4, $150 \mathrm{mM} \mathrm{NaCl}, 0.005 \%$ surfactant P20) in the range 0 to $68 \mathrm{nM}$, flowed over the immobilized mAb. For kinetic analysis the flow rate was maintained at $30 \mu \mathrm{l} / \mathrm{min}$, and data were collected at $25^{\circ} \mathrm{C}$. Data from a reference cell were subtracted to control for bulk refractive index changes. The Rmax was kept low and the flow rate high to eliminate mass transfer. All reagents used were of high purity and polished by size exclusion chromatography immediately before use to ensure removal of any aggregates. Data were evaluated using Biacore Evaluation Software (GE Healthcare).

\section{In Vivo Testing of mAbs}

To test in vivo $\mathrm{mAb}$ that blocked mouse complement in hemolysis assays, wild type (WT) mice (C57BL/6J, bred in house) were administered $\mathrm{mAb}$ by IP injection (1 $\mathrm{mg}$ in PBS, $40 \mathrm{mg} / \mathrm{kg}$ dose); controls included the blocking anti-mouse C5 mAb BB5.1 at the same dose. Blood was collected before mAb administration and at intervals up to $48 \mathrm{~h}$ after for measurement of hemolytic activity.

To test $\mathrm{mAb}$ that blocked human complement in hemolysis assays, $\mathrm{C} 7$ deficient mice (homozygous $\mathrm{C} 57 \mathrm{BL} / 6 \mathrm{NJ}-\mathrm{C} 7^{\text {em1(IMPC) }}$ $\mathrm{J} / \mathrm{Mmjax}$, bred in house, $\mathrm{n}=10$ ) were injected intraperitoneally (IP) with human C7 $(500 \mu \mathrm{g})$, then split into test and control groups (5 in each). One hour later, test group animals were injected subcutaneously (SC) with blocking $\mathrm{mAb}$ (1 mg in PBS, $40 \mathrm{mg} / \mathrm{kg}$ dose), while control group mice were injected with an 
irrelevant $\mathrm{mAb}$ at the same dose; blood was collected from all the animals just before the experiment, $1 \mathrm{~h}$ after $\mathrm{C} 7$ administration (immediately before giving the $\mathrm{mAb}$ ) and at intervals after $\mathrm{mAb}$ injection up to $48 \mathrm{~h}$ for measurement of hemolytic activity.

To test $\mathrm{mAb}$ that blocked rat complement in hemolysis assays, Lewis rats (100-150 g; Charles River Laboratories, Edinburgh, UK) were injected IP with 10,20 or $40 \mathrm{mg} / \mathrm{kg}$ dose of $\mathrm{mAb}$ (2 per group); blood was collected from all the animals just before the experiment, and at intervals post-injection over a time course of 7 days for measurement of hemolytic activity.

\section{Testing $\mathrm{mAb}$ in an Experimental Autoimmune Myasthenia Gravis (EAMG) Rat Model}

A rat complement-blocking $\mathrm{mAb}$ was tested in the rat EAMG model. Lewis rats (100-150 g) were injected IP with antiAcetylcholine receptor (AChR) $\mathrm{mAb} 35$ at $1 \mathrm{mg} / \mathrm{kg}$ in $\mathrm{PBS}$ as described previously (16-18). mAb35 binds the main immunogenic region of $\mathrm{AChR}$, activating complement and damaging the neuromuscular junction endplates, causing severe damage to motor function. Animals were assessed hourly post-disease initiation as described previously. Clinical symptoms were assigned based on a standardized scale 0 to 5 : 0 , no disease; 1, reduced grip strength in front legs (can grip cage lid but cannot lift) and floppy tail; 2, loss of grip in front legs; 3, loss of grip and hind limb weakness and wasting; 4, loss of grip and hind limb paralysis; 5, moribund. mAb35-injected rats were split into two groups ( $\mathrm{n}=5$ each), the test group received blocking $\mathrm{mAb}$ at $10 \mathrm{mg} / \mathrm{kg} \mathrm{SC}$ (determined in the dosing experiment) at time zero, the control group received an irrelevant isotype control antibody (D1.3) at the same times, routes and doses. Blood was taken at intervals for hemolysis assays; all animals were sacrificed at $48 \mathrm{~h}$ post-induction.

Soleus muscles were harvested and frozen in OCT mounting medium for sectioning as described previously (16-18). Sections were fixed in ice-cold acetone for $15 \mathrm{~min}$ at $-80^{\circ} \mathrm{C}$ and then blocked for $30 \mathrm{~min}$ in $10 \%$ horse serum/2\% BSA. After washing in $\mathrm{PBS}$, sections were stained overnight at $4^{\circ} \mathrm{C}$ with primary antibodies, $\mathrm{C} 3 / 30$ anti-C3b/iC3b mAb (in house) at $10 \mu \mathrm{g} / \mathrm{ml}$, and rabbit anti-rat C9/MAC polyclonal IgG (in house) at $50 \mu \mathrm{g} /$ $\mathrm{ml}$, both in the block buffer. Anti-C3b/iC3b sections were washed and incubated for $15 \mathrm{~min}$ at RT with amplifier antibody goat anti-mouse (VectaFluor DyLight 488, \# DK-2488; Vector Labs, Peterborough, UK). After washing, secondary antibody, horse anti-goat IgG-Alexa Fluor 488 (DyLight 488, \# DK2488) for C3b/iC3b or goat anti-rabbit-FITC (\#45002; Oxford Biomedical Research, Rochester Hills, MI, USA) for anti-C9/MAC were added as appropriate, together with $\alpha$-bungarotoxin-TRITC (BtX) (labels AChR; Boitum, \# 00012) at 0.5\% and Hoechst stain 1: 10000 dilution (\# 62249; ThermoFisher), then incubated $40 \mathrm{~min}$ at RT in the dark. Sections were washed in PBS and mounted in VectorShield Vibrance (\#H-1700-2; Vector Labs) before analysis using an Apotome fluorescence microscope (Zeiss Apotome Axio Observer microscope, Carl Zeiss Microscopy, Cambridge, UK). Ten fields were captured from comparable regions of muscle in each sample at the same exposure and magnification $(\times 20)$ and the number of BuTxreactive endplates in each section was measured using density slicing in an image analysis system (Image), University of Wisconsin-Maddison, Maddison, WI, USA). For co-localization of complement activation products, sections were additionally imaged on a Zeiss confocal microscope (Zeiss LSM800 confocal laser scanning microscope).

\section{Statistical Analysis}

All statistical analyses were performed using GraphPad Prism software (v. 5.0, San Diego, California). Statistical significance between two groups was obtained using the unpaired t-test and for multiple groups using one-way ANOVA after testing for normality. For all analyses, $\mathrm{p}<0.05$ was considered significant. Error bars in all figures represent mean \pm standard error of triplicates (unless otherwise stated. The SPR analysis was performed in an automated manner using T200 Biacore Evaluation Software version 2 (GE Healthcare).

\section{RESULTS}

\section{The Novel Blocking mAb Work Across Species and Block Hemolysis by Binding C7 and/or the C5b-7 Complex}

In total, 15 fusions were performed; 15,000 hybridoma clones were generated and screened, 7 confirmed to be inhibitory, and

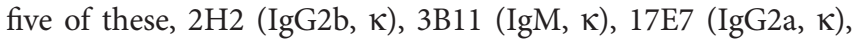
59E7 (IgG2b, א), and 73D1 (IgG2a, א), chosen for full characterization based upon the capacity of clone supernatants to cause inhibition of CP hemolysis of ShEA by NHS, NRS or NMS. All selected $\mathrm{mAbs}$ except $\mathrm{mAb} 17 \mathrm{E} 7$ were generated in $\mathrm{C} 7$ KO mice; 17E7 was produced in a WT mouse. All mAbs except $3 \mathrm{~B} 11$ were purified using protein $\mathrm{G}$ chromatography, $\mathrm{mAb} 3 \mathrm{~B} 11$, an IgM mAb, was purified using ammonium sulphate precipitation. The purified $\mathrm{mAbs}$ were tested in hemolysis assays with different species sera (Figures 1A-D). Anti-C5 blocking mAbs were used as positive controls; commercial mAbs eculizumab and crovalimab for NHS, BB5.1 for NMS and in house mAb 7D4 for NRS $(18,19)$. As expected from the selection process, each of the selected $\mathrm{mAbs}$ efficiently inhibited CP hemolysis in one or more species sera; In NHS, mAbs 17E7, 59E7, 3B11 and 73D1 all inhibited in that order of efficiency; $2 \mathrm{H} 2$ inhibited weakly (Figure 1A). In NMkS 59E7, 73D1, and 17E7 inhibited in that order of efficiency; no inhibition was observed with 2H2 (Figure 1D). In NRS, $2 \mathrm{H} 2$ was an exceptionally strong inhibitor, at least ten-fold better than other mAbs in the assay; 73D1 and 3B11 also inhibited NRS in that order of efficiency, but 17E7, 59E7, and the commercial anti-human C5 mAb had no inhibitory activity in NRS (Figure 1B). In NMS, mAbs 73D1, $2 \mathrm{H} 2$, and $3 \mathrm{~B} 11$ inhibited in that order of efficiency, but 17E7, 59E7, and the C5-blocking controls 7D4 and eculizumab had no inhibitory activity in NMS (Figure 1C). The 73D1 inhibition profile closely matched that of BB5.1, the blocking anti-C5 mAb used as positive control in this assay; crovalimab also inhibited NMS as previously reported (Figure 1C) (19). None of the new 
A

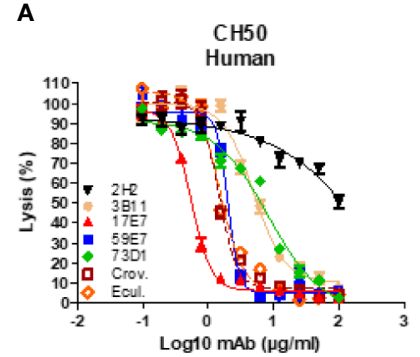

C

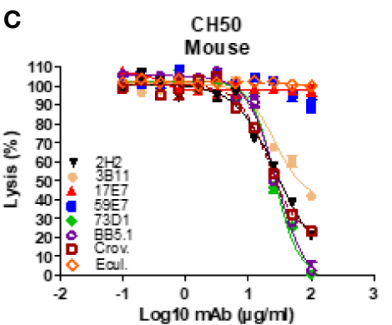

E

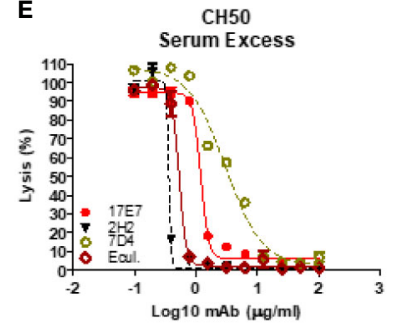

G

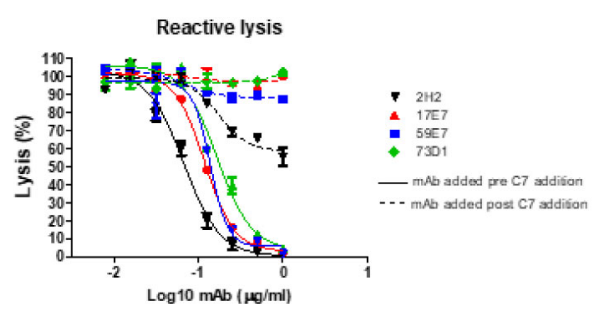

B

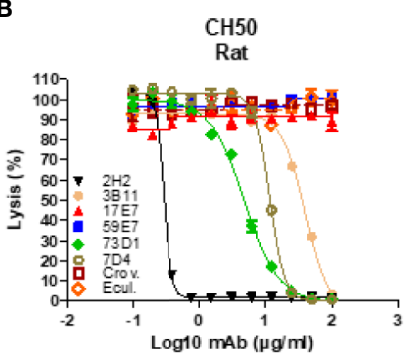

D

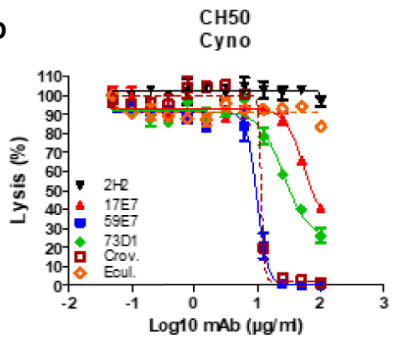

$\mathbf{F}$

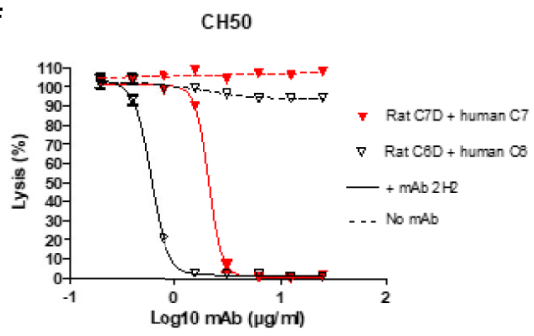

H

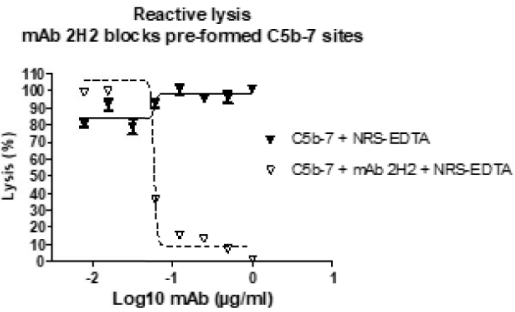

FIGURE 1 | Functional assays of C7-blocking mAbs. (A-D) Anti-C7 mAb were tested for blocking activity in classical pathway (CP) hemolysis (CH50) assays across species. Sera tested were human (A), rat (B), mouse (C) and cynomolgus monkey (Cyno) (D). Anti-C5 mAb crovalimab (Crov), eculizumab (Ecul), BB5.1 and 7D4 were used as comparators. Test and control mAb were titrated in range $0-100 \mu \mathrm{g} / \mathrm{ml}$. (E) Serum excess assay using NHS or NRS concentration 10-fold that used in the standard CP assay; solid lines are NHS, dashed lines are NRS. (F) human C6D and C7D were reconstituted with purified human C6 or C7 (dashed lines) respectively and the capacity of $\mathrm{mAb} 2 \mathrm{H} 2$ to inhibit hemolysis tested. (G, $\mathbf{H})$ Reactive lysis assays using guinea pig erythrocytes (GpE) as target; for mAb 17E7, 59E7, and 73D1, purified human complement proteins (C5b6, C7, C8 and C9) were used; for mAb 2H2 and 73D1 human C5b6 and rat C7 were used with normal rat serum (NRS) as the source of rodent C8 and C9. The mAb were either added to GpE-C5b6 before or after C7 addition (G); solid and dotted line respectively. mAb $2 \mathrm{H} 2$ was added to washed GPE- C5b-7 (rat) prior to addition of NRS as source of C8 and C9 $\mathbf{( H )}$. All experiments were repeated three times with the same results. The error bars are standard errors of triplicates.

mAb inhibited in NRbS (negative data not shown). The crossspecies inhibitory activities of the mAbs are summarized in Table 1; the calculated 50\% complement inhibitory doses and hemolytic units (HU) of all $\mathrm{mAbs}$ in the different sera are shown. Serum excess assays (25\% serum; 10 -fold serum dose compared to titration assays above) were used to test $\mathrm{mAb} 17 \mathrm{E} 7$ and $2 \mathrm{H} 2$ in conditions that better reflect those prevailing in whole blood (Figures 1E, F), confirming that these mAbs are efficient complement inhibitors in human and rat serum respectively.

To identify the precise mechanism of complement inhibition by the novel $\mathrm{mAbs}$, reactive lysis assays were used. GPE were first incubated with C5b6; blocking mAbs $(17 \mathrm{E} 7,59 \mathrm{E} 7,73 \mathrm{D} 1,2 \mathrm{H} 2)$ at 
TABLE 1 | Summary of novel anti-C7 and control anti-C5 blocking mAb tested.

\begin{tabular}{|c|c|c|c|c|c|}
\hline Antibody & Isotype & Species & $\begin{array}{l}\text { Hemolytic } \\
\text { Units (HU) }\end{array}$ & $\begin{array}{l}\mathbf{5 0 \%} \text { Inhibitory } \\
\text { Dose (ng/ml) }\end{array}$ & Reactivity \\
\hline \multicolumn{6}{|c|}{ mAb anti-C7 } \\
\hline \multirow[t]{2}{*}{ 17E7 } & $\operatorname{lgG} 2 \mathrm{a}, \mathrm{\kappa}$ & Human & 55.1 & 181.6 & Strong \\
\hline & & Monkey & 1.9 & 530.3 & Strong \\
\hline \multirow[t]{2}{*}{$59 \mathrm{E} 7$} & $\operatorname{lgG} 2 b, \kappa$ & Human & 47.7 & 209.7 & Strong \\
\hline & & Monkey & 10.1 & 98.7 & Strong \\
\hline \multirow[t]{2}{*}{ 3B11 } & $\lg M, \kappa$ & Human & 19.9 & 501.9 & Strong \\
\hline & & Rat & 11.9 & 839.5 & Moderate \\
\hline \multirow[t]{3}{*}{$2 \mathrm{H} 2$} & $\lg G 2 b, \kappa$ & Human & 1.0 & 9977.0 & Weak \\
\hline & & Rat & 264.8 & 33.9 & Strong \\
\hline & & Mouse & 2.7 & 3715.4 & Weak \\
\hline \multirow[t]{4}{*}{ 73D1 } & $\operatorname{lgG} 2 \mathrm{a}, \mathrm{k}$ & Human & 17.2 & 581.8 & Strong \\
\hline & & Monkey & 3.8 & 261.1 & Strong \\
\hline & & Rat & 19.8 & 505.5 & Strong \\
\hline & & Mouse & 13.9 & 720.3 & Strong \\
\hline \multicolumn{6}{|c|}{$\mathrm{mAb}$ anti-C5 controls } \\
\hline \multirow[t]{2}{*}{ 7D4 } & $\lg G 2 b, \kappa$ & Human & 69.3 & 144.2 & Strong \\
\hline & & Rat & 9.5 & 1054.4 & Moderate \\
\hline BB5.1 & $\lg G 1, \kappa$ & Mouse & 16.3 & 613.6 & Strong \\
\hline \multirow[t]{3}{*}{ Crovalimab } & $\lg G 1, \kappa$ & Human & 49.9 & 212.3 & Strong \\
\hline & & Monkey & 8.6 & 115.5 & Strong \\
\hline & & Mouse & 1.4 & 1862.1 & Weak \\
\hline Eculizumab & $\lg G 2 /$ & Human & 47.1 & 181.6 & Strong \\
\hline & $4, \kappa$ & & & & \\
\hline
\end{tabular}

Inhibitory dose: <750, strong; 750-1500, moderate; >1500, weak.

various doses $(0-1 \mu \mathrm{g} / \mathrm{ml})$ added either before or after C7 addition, followed by $\mathrm{C} 8$, C9. All mAb except $2 \mathrm{H} 2$ were tested with purified human proteins; for $\mathrm{mAb} 2 \mathrm{H} 2$, purified rat $\mathrm{C} 7$ and EDTA-NRS as a source of rat C8 and C9 were used with human C5b6. All the 22 tested mAbs showed strong inhibition when added to GPE-C5b6 before C7 was added. When added after C7, mAb 17E7, 59E7, and 73D1 all showed no inhibition of lysis (Figure 1G). To further test the mode of inhibition of mAb 17E7 the $\mathrm{mAb}$ was either pre-incubated with $\mathrm{C} 7$ prior to addition to GPE-C5b6 or added simultaneously with C7; inhibition of lysis was essentially the same with or without the pre-incubation step, suggesting that the mAb efficiently captures fluid-phase C7 to prevent formation of an active C5b-7 complex (data not shown).

In contrast to the other $\mathrm{mAb}$, the rat-selective mAb $2 \mathrm{H} 2$ caused a dose-dependent inhibition of lysis even when added to pre-formed GPE-C5b-7, implying that this mAb had a distinct mechanism of inhibition compared to the other $\mathrm{mAb}$, working at least in part by binding and blocking C5b-7 thus preventing C8 binding to the complex (Figure 1H). When tested in a reactive lysis system using human $\mathrm{C} 5 \mathrm{~b} 6$, rat $\mathrm{C} 7$ and either human $\mathrm{C} 8 / \mathrm{C} 9$ or NRS as a source of $\mathrm{C} 8 / \mathrm{C} 9, \mathrm{mAb} 22 \mathrm{H} 2$ effectively blocked lysis when incubated with pre-formed GPE-C5b-7 (rat) and washed to remove free $\mathrm{mAb}$ prior to addition of either human $\mathrm{C} 8 / \mathrm{C} 9$ or NRS, confirming the findings with human $\mathrm{C} 7$ above and demonstrating that the species source of $\mathrm{C} 8 / \mathrm{C} 9$ (human or rat) did not impact the effect (Figure 1H). To further test species specificity of $\mathrm{mAb} 2 \mathrm{H} 2$, rat $\mathrm{C} 6 \mathrm{D}$ was reconstituted with human $\mathrm{C} 6$ and rat $\mathrm{C} 7 \mathrm{D}$ with human $\mathrm{C} 7$; in each case, $2 \mathrm{H} 2$ strongly inhibited lysis in a dose-dependent manner, implying that this $\mathrm{mAb}$ is selective for the C5b-7 complex (Figure 1F).

\section{The Novel mAbs Bind Native $\mathrm{C} 7$ and $\mathrm{C} 7$ in the TCC Complex in Serum}

The direct ELISA showed that all the selected new mAbs recognized human $\mathrm{C} 7$; $\mathrm{mAb} 2 \mathrm{H} 2,3 \mathrm{~B} 11$, and $73 \mathrm{D} 1$ also bound rat $\mathrm{C} 7$, while $\mathrm{mAb} 73 \mathrm{D} 1$ bound mouse $\mathrm{C} 7$. $\mathrm{mAb} 17 \mathrm{E} 7$ and 73D1 were strongly cross-reactive with non-human primate (cynomolgus) C7 (Figure 2A; Table 1). In competitive sandwich ELISA, C7 was not detected with any $\mathrm{mAb}$ pair suggesting that they compete for similar epitopes on C7; all $\mathrm{mAb}$ worked in sandwich ELISA with goat anti-C7 as either capture or detect (Figure 2B). mAb $2 \mathrm{H} 2$ when used as capture and goat anti-C7 as detection also detected rat $\mathrm{C} 7$, demonstrating that the $\mathrm{mAb}$ recognizes $\mathrm{C} 7$ from both species.

WB was used to confirm binding of mAbs to C7. The humanspecific mAb 59E7 and 17E7 detected C7 in human and cynomolgus monkey serum under NR conditions (Figure 3A); these $\mathrm{mAb}$ did not detect $\mathrm{C} 7$ in other species sera, confirming the ELISA results above. The species cross-reactive mAb 73D1 and 3B11 specifically detected C7 in human, rat, mouse and cynomolgus monkey sera under NR conditions (Figures 3B, C). None of the mAb detected $\mathrm{C} 7$ in sera under $\mathrm{R}$ conditions (negative data not shown). $\mathrm{mAb} 2 \mathrm{H} 2$ did not bind the human $\mathrm{C} 7$ standard, detected by all other mAbs; it did weakly detect C7 in all sera tested under NR conditions but also identified multiple high molecular weight bands in the MW range 160 to $260 \mathrm{kDa}$ that may represent $\mathrm{C} 7$ aggregates or terminal pathway complexes in serum (Figure 3D). To further explore the nature of these, pull-down assay from rat or human serum activated with zymosan and aggregated IgG in the presence of biotinylated $2 \mathrm{H} 2$ was performed; remarkably, mAb $2 \mathrm{H} 2$ pulled down all the terminal pathway proteins from both rat and human serum, indicating that it bound the fluid phase TCC when present during activation (Figures 3F, G). Pull-downs from activated human serum performed as above but using biotinylated $\mathrm{mAb}$ 17E7, 59E7, and 73D1, showed that each of the antibodies also pulled down all the terminal pathway proteins $\mathrm{C} 5 \mathrm{~b}-\mathrm{C}$, demonstrating capacity of each of these mAbs to bind C7 in the forming TCC (Figures 3H-J).

Binding of the novel mAbs to TCC when present during serum activation was confirmed in sandwich ELISA on pull-downs from rat or human serum using the mAbs as above. All terminal pathway proteins: $\mathrm{C} 5 \mathrm{~b}, \mathrm{C} 6, \mathrm{C} 7, \mathrm{C} 8$, and $\mathrm{C} 9$ were detected in the pull-downs; the strongest signals were observed with C5b, C6, and $\mathrm{C} 7$ proteins (Figure 2D). All the new $\mathrm{mAb}$ also bound the preformed TCC (captured on aE11 anti-C9 neospecific antibody) in activated human serum, giving signals at similar levels to the positive control E2 anti-C8 antibody, confirming that they bind C7 in the pre-formed TCC (Figure 2C). The aE11 mAb also captured TCC from activated rat serum and this was detected using the rat C7-reactive mAb 2H2 (Figure 2C). Taken together, the data show that each of the $\mathrm{mAb}$ recognize $\mathrm{C} 7$ in the TCC both when present in the fluid phase during TCC generation, and when added postactivation to the preformed complex.

SPR analysis on immobilized antibody with human or rat C7 flowed over confirmed binding of the novel mAbs to human and/ or rat C7. The measured kinetics/affinity are summarized in 
A

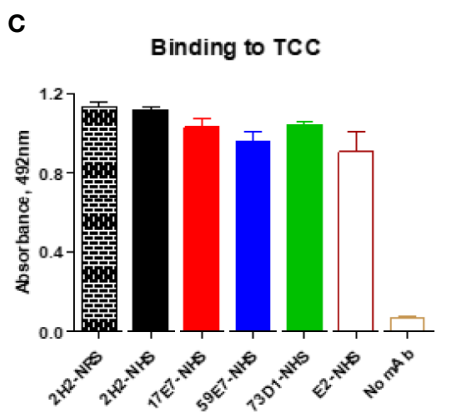

B

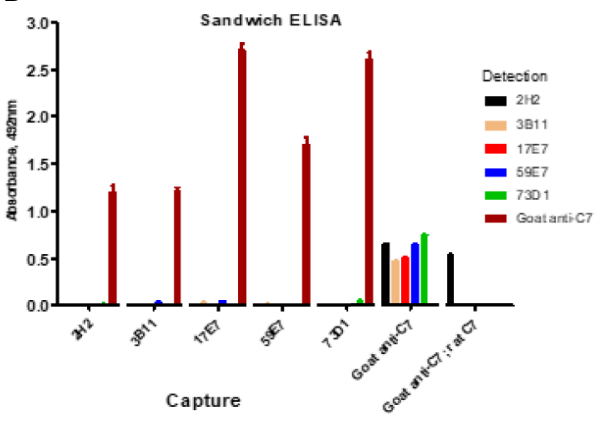

D

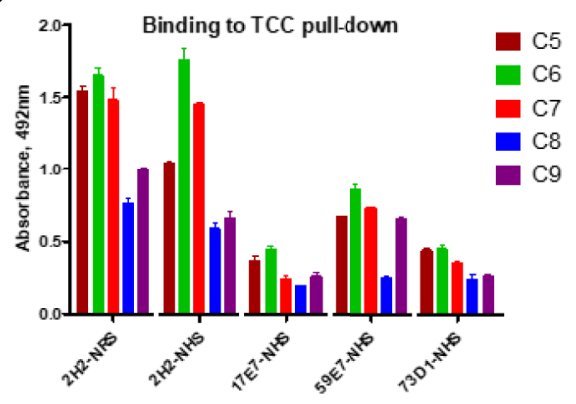

FIGURE 2 | Direct and sandwich ELISA to determine mAb binding to human, monkey, rat and mouse C7. (A) Direct ELISA: plates were coated with human, monkey (cyno), rat or mouse C7; mAbs were tested in a dilution series (0-10 $\mu \mathrm{g} / \mathrm{ml})$. The graph shows representative binding with the $10 \mu \mathrm{g} / \mathrm{ml}$ capture. (B) Sandwich ELISA: the new mAbs were paired as capture and detect with human $\mathrm{C} 7$ used in a dilution series $(0-5 \mu \mathrm{g} / \mathrm{ml})$. The graph shows representative binding with $5 \mathrm{\mu g} / \mathrm{ml} \mathrm{C7}$. As a positive control, polyclonal anti-C7 (goat anti-C7) was used as capture with each of the mAb as detect; rat C7 captured on goat anti-C7 (goat anti-C7; rat C7) was also tested with the mAb as detect. (C) Sandwich ELISA to detect pre-formed TCC in activated NHS; TCC in activated NHS (and NRS for 2H2) was captured on aE11 anti-C9 and the novel mAbs and the positive control E2 anti-C8 mAb used to detect the TCC complex captured. (D) TCC complexes generated in NHS (or NRS for $2 \mathrm{H} 2$ ) in the presence of each of the new mAb (biotinylated) were captured on avidin-coated plates, then polyclonal antibodies against each of the terminal complement proteins used to test the presence of the respective components in the complex. The error bars are standard errors of triplicates.

All experiments were repeated three times with the same results.

Table 2. The mAb 17E7 and 59E7 showed very strong binding to human C7 in SPR analyses $\left(\mathrm{KD}=1.02 \times 10^{-9}, 9.31 \times 10^{-10}\right.$ respectively) (Figure 3K) with negligible off rates, suggesting that 17E7 and 59E7 are promising candidates for human therapeutics. Binding of mAb 3B11 and 73D1 to human or rat C7 was relatively weak (human $\mathrm{KD}=2.30 \times 10^{-7}$ and $5.55 \times$ $10^{-8}$; rat $\mathrm{KD}=1.93 \times 10^{-7}$ and $8.17 \times 10^{-8}$ ) (Supplementary Figure 1); however, both these $\mathrm{mAb}$ showed a slow off rate for rat C7 offering promise for use in vivo. Additionally, mAb 73D1 showed strong binding to mouse $\mathrm{C} 7\left(\mathrm{KD}=2.31 \times 10^{-9}\right)$ with a very slow off rate, promising for testing in mouse models. Analysis by SPR of immobilized $2 \mathrm{H} 2$ showed no measurable binding to native human, rat or mouse $\mathrm{C} 7$ in multiple analyses (negative data not shown).

\section{The Novel mAbs Are Efficient Complement Inhibitors In Vivo}

The capacity of mAbs to inhibit complement in vivo was tested in mice and rats. To test the capacity of the anti-mouse $\mathrm{C} 7 \mathrm{mAb}$ $73 \mathrm{D} 1$ to inhibit complement in vivo, WT mice were administered
73D1 (or BB5.1 anti-mouse C5 as positive control) IP and complement activity in serum was tested at intervals over a time course of $48 \mathrm{~h}$. Complement was inhibited by both $\mathrm{mAb}$ over the full course of the experiment up to end-point at $48 \mathrm{~h}$ (Figure 4A). To test the capacity of the anti-human $\mathrm{C} 7 \mathrm{mAb}$ 17E7 to inhibit $\mathrm{C} 7$ in vivo, $\mathrm{mAb}$ was administered to $\mathrm{C} 7$-deficient mice reconstituted with human C7. Human C7 effectively restored hemolytic activity in the mice, and administration of $\mathrm{mAb} 17 \mathrm{E} 7$ efficiently inhibited hemolytic activity in the mice (>70\% inhibited at $3 \mathrm{~h}$ post-administration) compared to irrelevant antibody, demonstrating that the mAb blocked human $\mathrm{C} 7$ in vivo (Figure $\mathbf{4 B}$ ). The rat-selective mAb $2 \mathrm{H} 2$ was tested for complement inhibition in rats to determine dose requirement and antibody half-life. Rats were injected with $\mathrm{mAb}$ $2 \mathrm{H} 2$ at 10, 20, and $40 \mathrm{mg} / \mathrm{kg}$ and blood collected at intervals for testing hemolytic activity. Even at the lowest dose, the mAb was an effective inhibitor, blocking complement activity for $>48 \mathrm{~h}$, and at the highest dose blocked complement for at least a week (Figure 4C). The 10-mg/kg dose was used for the EAMG experiment described below. 


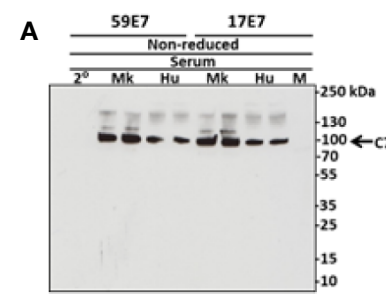

C

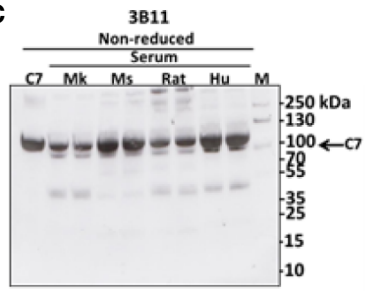

E
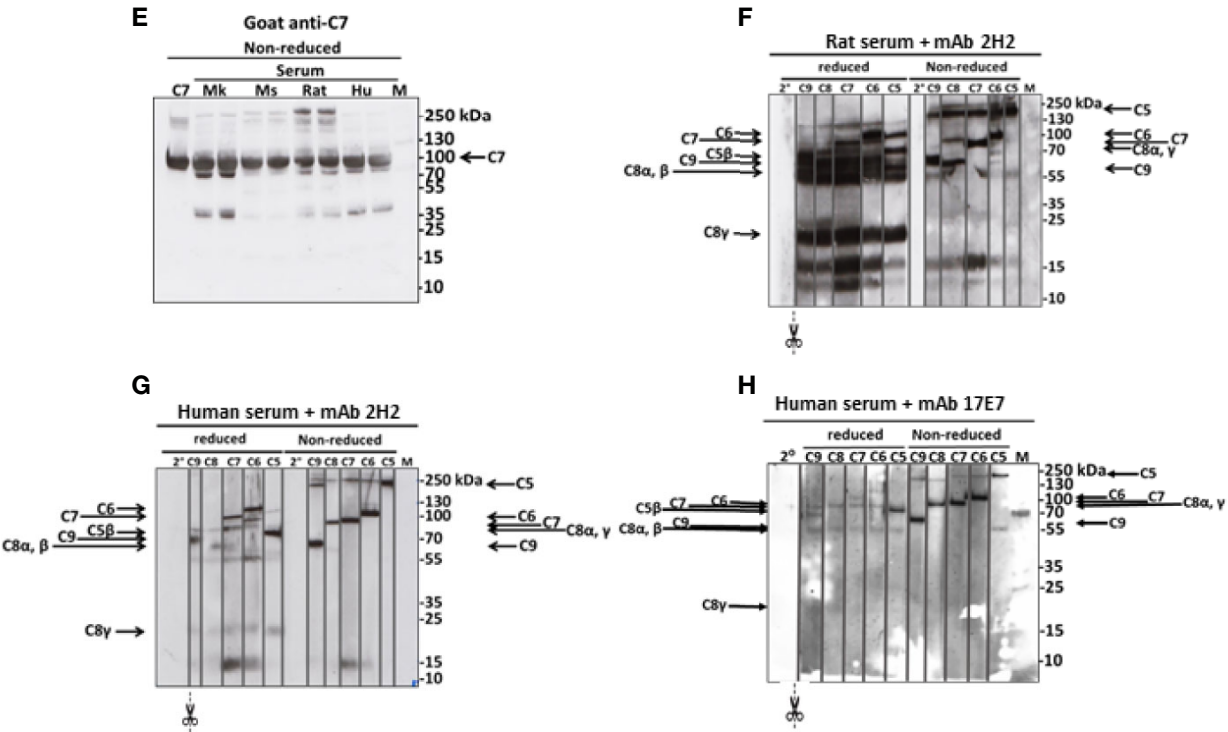

B

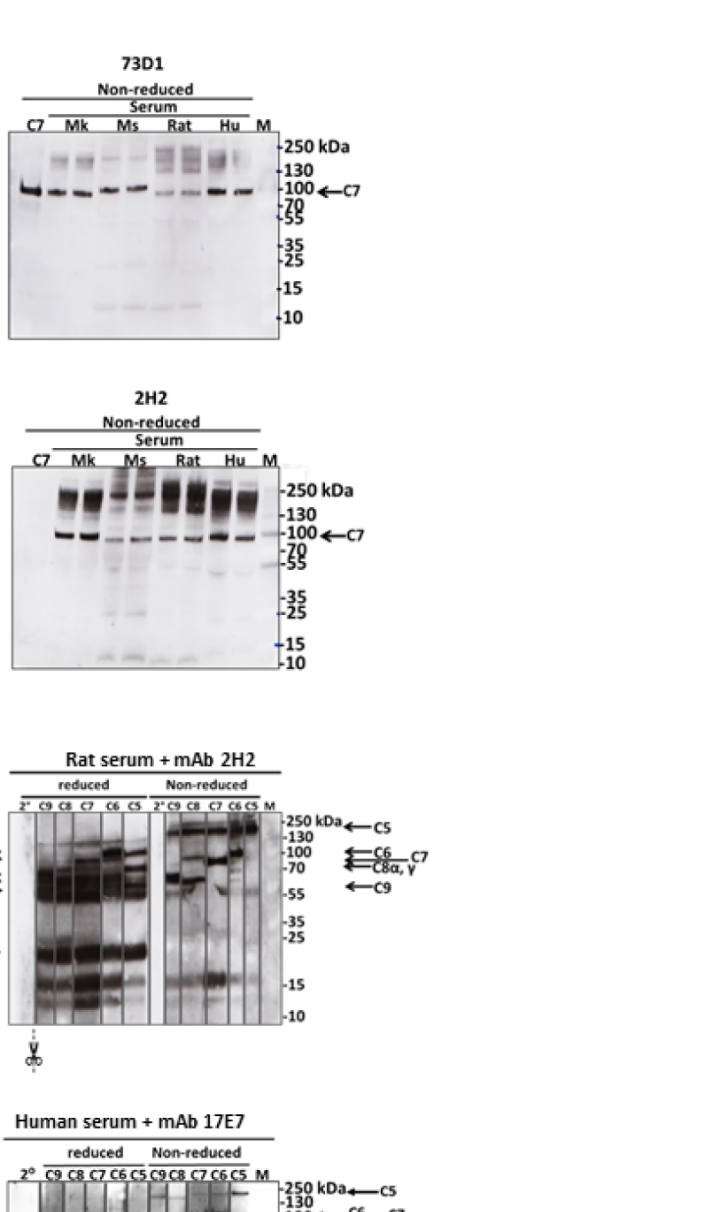

D

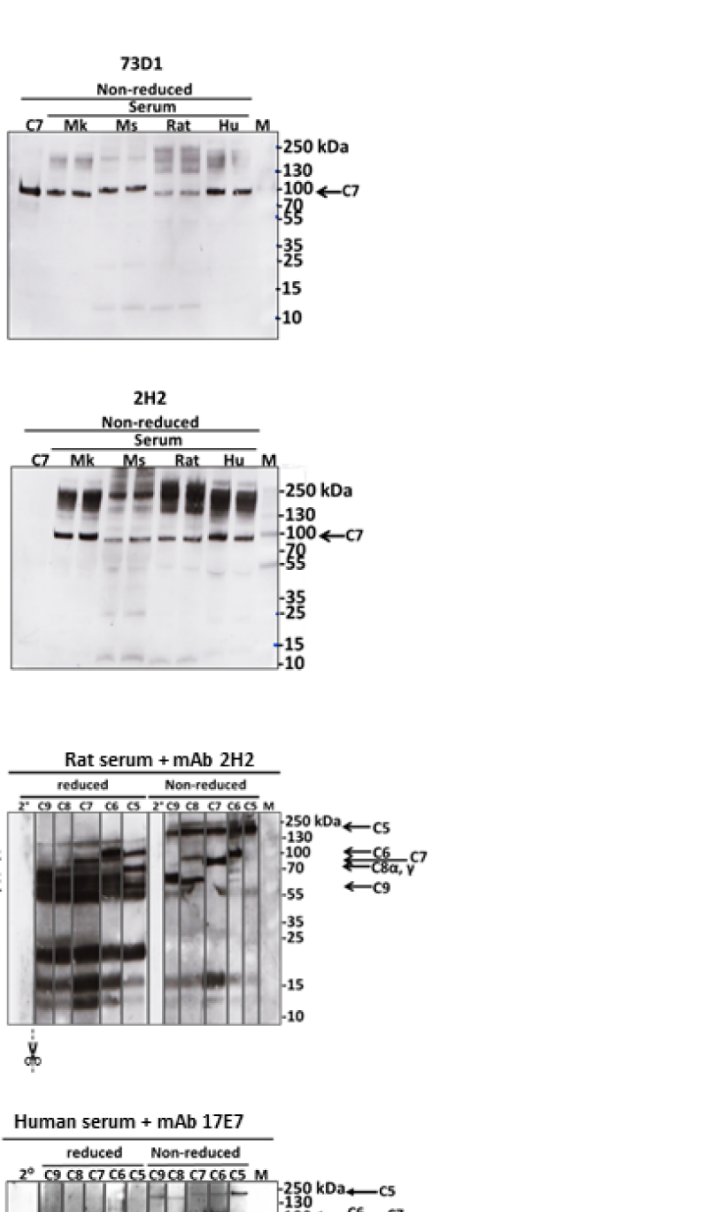

F

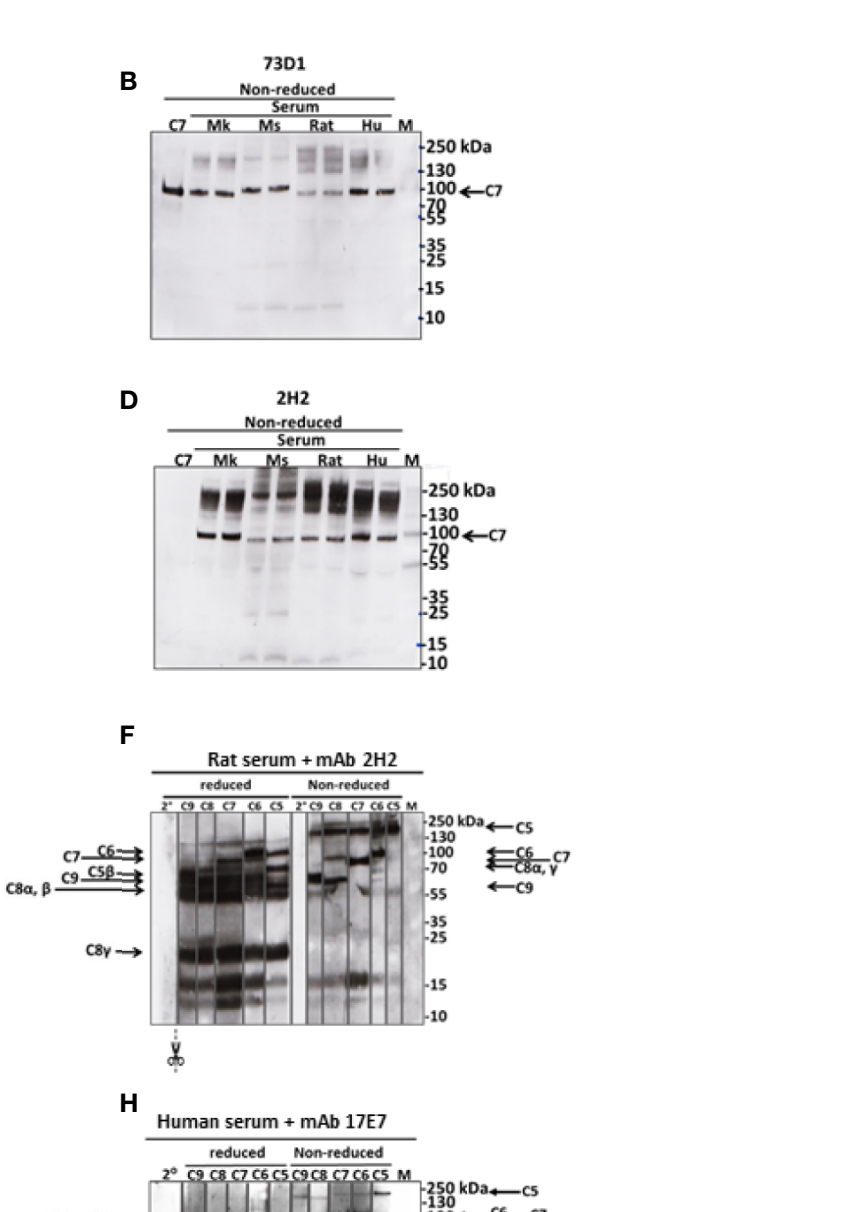

H

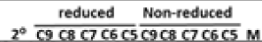




\begin{abstract}
FIGURE 3 | Western blotting to detect C7 binding in serum and in TCC. (A) The human-specific mAbs 59E7 and 17E7 were used to probe WB of NHS (Hu) and Cynomolgus monkey (Mk) serum under non-reducing (NR) conditions. Secondary only control was included ( $\left.2^{\circ}\right)$. (B-E) The cross-species reactive mAbs $73 D 1$ (B), 3B11 (C) and 2H2 (D) and as control the polyclonal goat anti-C7 (E) were used to probe WB of NHS (Hu), monkey (Mk), mouse (Mo) and rat sera; purified human C7 was used as standard. All sera were run in duplicate. Polyclon3B11 (C), $2 \mathrm{H} 2$ (D), and positive control goat anti-C7 (E). Results are representative of three independent experiments. M; protein molecular weight marker. (F-J) The novel mAbs were used to pull down complexes from activated serum; these were then run on WB under non-reduced and reduced conditions and probed with polyclonal antibodies against each of the terminal complement proteins. $\mathrm{mAb} 2 \mathrm{H} 2 \mathrm{was}$ used in rat $\mathbf{( F )}$ and human $(\mathbf{G})$ serum; the other mAbs in human serum only $\mathbf{( H - J ) . ~ T h e ~ b l o t s ~ w e r e ~ c u t ~ i n t o ~ s t r i p s ~ p r i o r ~ t o ~ p r o b i n g ~ t o ~ d e t e c t ~ t h e ~ i n d i v i d u a l ~ t e r m i n a l ~ p a t h w a y ~}$

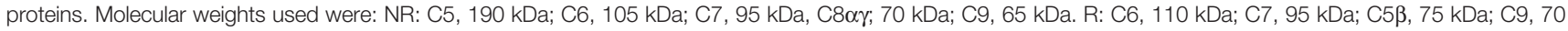
$\mathrm{kDa} ; \mathrm{C} 8 \alpha / \beta, 65 \mathrm{kDa}$; C8 $\gamma, 22 \mathrm{kDa}$. Results are representative of at least three analyses. M; protein molecular weight marker, $2^{\circ}$; secondary antibody. (K) The novel mAbs 17E7, 59E7 and 73D1 were separately immobilized on mouse IgG capture sensor chips (GE Healthcare, \# BR-1008-38) and mAb 3B11 (IgM) on protein L Series S sensor chip (GE Healthcare \#29-2051-38) at approximately 60 RU. Human, rat or mouse C7 was flowed in HEPES-buffered saline (HBS) in a dilution range of 66 to $8 \mathrm{nM}$ and interactions with the immobilized mAbs were analyzed. Sensorgrams were collected and KDs were calculated using the Langmuir 1: 1 binding model with RI values set to zero. Representative sensorgrams for 17E7 and 59E7 binding of human C7 are shown with raw data in colored lines and fitted data in dotted line (average of 3); all binding data and analyses are included in Table 2. The sensorgrams of clones 3B11 and 73D1 are included in Supplementary. The SPR analysis was performed in an automated manner using T200 Biacore Evaluation Software version 2 (GE Healthcare).
\end{abstract}

TABLE 2 | SPR analysis of the binding of C7 to the immobilized mAb.

\begin{tabular}{|c|c|c|c|}
\hline Antibody & KD (M) & $\mathrm{Ka}(1 / \mathrm{Ms})$ & $\mathrm{Kd}(1 / \mathrm{s})$ \\
\hline 17E7 & Human; $1.02 \times 10^{-9}$ & $6.83 \times 10^{4}$ & $6.94 \times 10^{-5}$ \\
\hline 59E7 & Human; $9.31 \times 10^{-10}$ & $1.45 \times 10^{6}$ & $1.4 \times 10^{-3}$ \\
\hline \multirow[t]{2}{*}{ 3B11 (protein L captured) } & Human; $2.30 \times 10^{-7}$ & $5.05 \times 10^{3}$ & $1.20 \times 10^{-3}$ \\
\hline & Rat; $1.93 \times 10^{-7}$ & $2.91 \times 10^{3}$ & $5.61 \times 10^{-4}$ \\
\hline \multirow[t]{3}{*}{ 73D1 } & Human; $5.55 \times 10^{-8}$ & $2.63 \times 10^{4}$ & $1.5 \times 10^{-3}$ \\
\hline & Rat; $8.17 \times 10^{-8}$ & $6.98 \times 10^{3}$ & $5.70 \times 10^{-4}$ \\
\hline & Mouse; $2.31 \times 10^{-9}$ & $1.02 \times 10^{5}$ & $2.36 \times 10^{-4}$ \\
\hline
\end{tabular}

\section{The Rat-Selective mAb 2H2 Prevents Clinical Disease and Pathology in a Myasthenia Model}

EAMG was passively induced in rats; at the time of disease induction, the rat-selective $\mathrm{mAb} 2 \mathrm{H} 2$ or isotype control $(10 \mathrm{mg} / \mathrm{kg}$; 5 per group) was administered SC. As expected, all isotype control treated rats began to lose weight and show symptoms, comprising limp tails, piloerection, hind limb weakness and reduced grip strength within $24 \mathrm{~h}$; all had a clinical score of 4 by endpoint (Figures 4D, E). (15-17) In contrast, animals given $\mathrm{mAb} 2 \mathrm{H} 2$ subcutaneously at the time of disease induction continued to gain weight over the time course of the experiment and did not develop detectable weakness or other clinical manifestations for the duration of the experiment (Figures 4D, E). Animals were sacrificed by a Schedule 1 method when weight loss was equal to or exceeded $20 \%$ of original bodyweight, when clinical score reached 4 , or at the $48 \mathrm{~h}$ endpoint. $\mathrm{CP}$ hemolytic activity in serum was absent in the $2 \mathrm{H} 2$ treated group throughout the experiment (Figure $\mathbf{4 F}$ ). As expected, serum from the untreated control animals retained full hemolytic activity across the time course. Soleus muscles were harvested at sacrifice, stained with $\alpha$-Bungarotoxin-TRITC and receptor numbers quantified. The number of endplates in isotype control treated animals was significantly lower than in $\mathrm{mAb} 2 \mathrm{H} 2$-treated animals ( $\sim$ three-fold less; $\mathrm{P}<0.0001$, Figure $4 \mathbf{G})$; endplate numbers in the $2 \mathrm{H} 2$-treated rat were comparable to numbers in naïve animals (data not shown). Endplates in muscles from the EAMG group were frequently fragmented, whereas most endplates in the $2 \mathrm{H} 2$-treated group were intact and linear, as in naïve animals. There was no significant difference in $\mathrm{C} 3$ fragment staining between the $2 \mathrm{H} 2$-treated and isotype control-treated animals $(\mathrm{P}=0.9792$, Figure $\mathbf{4 H})$; however, the intensity of C9/MAC staining was reduced more than threefold in the $2 \mathrm{H} 2$-treated group $(\mathrm{P}=0.0011$, Figure $4 \mathrm{I})$. Confocal analysis demonstrated co-localization of $\mathrm{C} 3 \mathrm{~b} / \mathrm{iC} 3 \mathrm{~b}$ and C9/MAC deposition at the endplate in isotype control animals at $48 \mathrm{~h}$ (Figure 4J); in 2H2-treated animals, $\mathrm{C} 3 \mathrm{~b} / \mathrm{iC} 3 \mathrm{~b}$ was deposited to a similar degree at endplates but C9/MAC deposition was weak or absent (Figure 4K).

\section{DISCUSSION}

The pathological role of complement in diverse diseases has been apparent for more than 50 years (20-23). Despite this long history, to date the use of anti-complement drugs has been restricted to a handful of rare diseases, including hemolytic disorders such as PNH and renal diseases, notably aHUS, where they have had a transformational impact (1-3). Eculizumab was first approved for treatment of $\mathrm{PNH}$ thirteen years ago, but only very recently have new anti-complement drugs reached the market and disease targets remain restricted to rare conditions (1). Recent reports provide irrefutable evidence that complement drives pathology in more common diseases including multiple sclerosis, NMOSD and AMD (24-26); however, because of the cost and route of administration, use of eculizumab in these diseases is not feasible; more affordable and effective drugs are needed. Complement proteins are abundant in plasma ( $\sim 5 \%$ of total plasma protein), and the majority are acute phase reactants, increasing synthesis and plasma concentration in response to infection. This is a particular issue for C5 blockade; breakthrough hemolysis is a recognized complication in patients on eculizumab, likely because even a tiny amount of free $\mathrm{C} 5(<0.1 \%)$ is sufficient to restore hemolytic activity (27-29). These issues led us to consider other targets in the terminal pathway; we focused on C7 for four reasons: i). Plasma concentrations of $\mathrm{C} 7$ are lower than those of C5 ( 2-fold lower molar concentration); ii). Unlike the other terminal pathway components, C7 is not synthesized by hepatocytes and is not an acute phase reactant, hence levels of C7 are stable in acute phase conditions (30); iii). Blocking C7 is likely to be less of an infection hazard compared to C5 blockade because C5a-mediated neutrophil recruitment is unimpaired indeed, the majority of patients with C7 deficiency are healthy, although at increased risk of Neisserial infections (31); iv). 


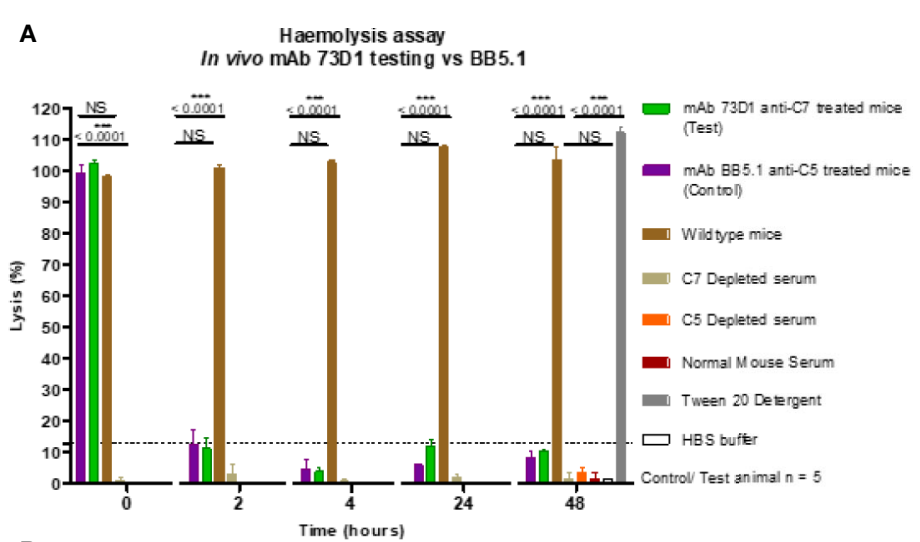

B

In vivo MAb 17 anti-C7 testing

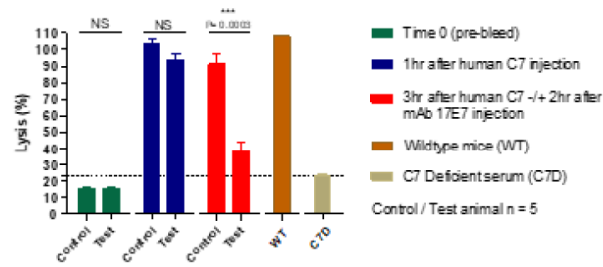

C

D

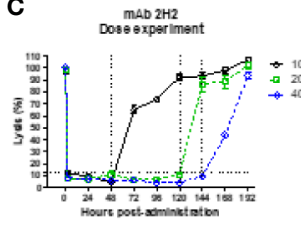

weightioss

E

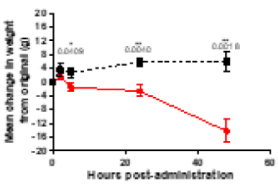

Cllnkeal scors

F Haemolysis assay
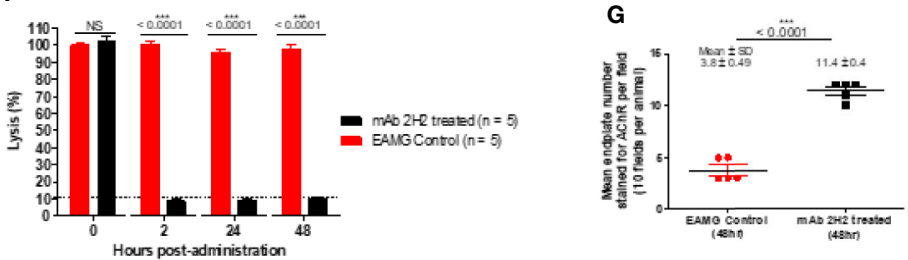

H

1

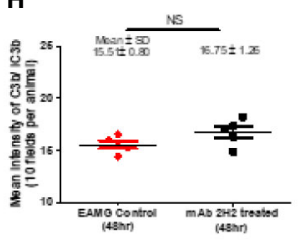

J

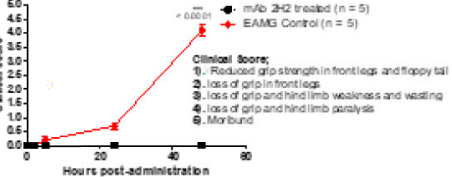

EAMG Control (48h)
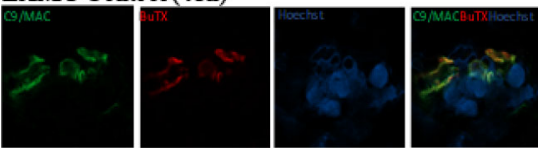

K

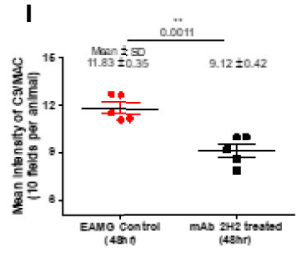

EAMG Test (2H2-treated, 48h)
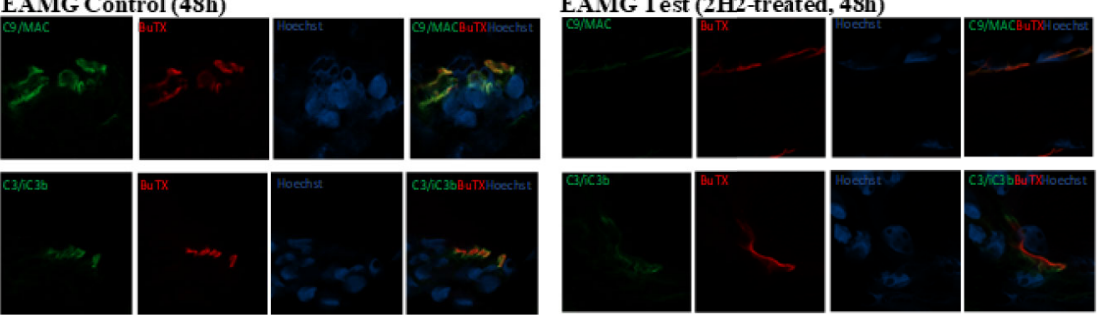

FIGURE 4 | Continued 


\begin{abstract}
FIGURE 4 | Testing anti-C7 mAbs in vivo. (A) mAb 73D1 or BB5.1 anti-mouse C5 as positive control was administered IP at a dose of 1 mg/kg to female wildtype mice ( $n=5$ per group); blood was sampled at intervals serum obtained and added to human C7D or C5D serum respectively prior to measuring CP hemolytic activity measured. Controls included C7D and C5D human sera at the same dose, NMS to demonstrate the requirement for human depleted sera and $1 \%$ Tween-20 and HBS to set $100 \%$ and $0 \%$ lysis in the assay. Significance of differences between groups was determined by one-way ANOVA; significant differences and p values are shown in the figure. Error bars are standard errors of triplicates. (B) C7-deficient mice (10 females) were reconstituted with human C7 (500 $\mathrm{Mg}$; IP), then split into test and control groups (5 in each). After $1 \mathrm{~h}$, test and control animals were injected subcutaneously (SC) with 17E7 mAb or irrelevant isotype control mAb (1 mg) respectively. Blood was collected prior to administration of $\mathrm{C}$, immediately prior to administration of $\mathrm{mAb}$ and $3 \mathrm{~h}$ after $\mathrm{mAb}$ administration. Hemolytic activity was measured as above. Significance of differences between groups was determined using an unpaired test; significant differences and $p$ values are shown in the figure. Error bars are standard errors of triplicates. (C) Female Lewis rats were divided into three groups $(\mathrm{n}=2 \mathrm{each})$ and injected intraperitoneally with $\mathrm{mAb} 2 \mathrm{H} 2$ at doses of 10,20 , and $40 \mathrm{mg} / \mathrm{kg}$; blood was collected from all the animals just before mAb administration, $2 \mathrm{~h}$ after $\mathrm{mAb} 2 \mathrm{H} 2$ administration, and then every $12 \mathrm{~h}$ over 1 week. Sera prepared and hemolytic activity tested in standard CP assays. Significance of differences between groups was determined using an unpaired t test; significant differences and $p$ values are shown in the figure. Error bars are standard errors of triplicates. (D-F) EAMG was induced in rats (5 per group) and either $\mathrm{mAb} 2 \mathrm{H} 2$ or isotype control mAb(10mg/kg) administered at induction. Weight loss (D) and clinical score (E) were measured at intervals; mice were bled at $0,2,24$, and $48 \mathrm{~h}$, serum harvested and hemolytic activity measured (F). All animals were killed at $48 \mathrm{~h}$. Results are means of five in each group and vertical bars represent $\mathrm{SD}$. Significance of differences between groups was determined using an unpaired $t$ test except panel $\mathrm{E}$ where paired $\mathrm{t}$ test was used; significant differences and $\mathrm{p}$ values are shown in the figures. (G-K). Soleus muscles were harvested at time of sacrifice (48 h) and snap frozen in OCT. Sections (10 $\mu$ m) were stained for AChR with TRITC-conjugated a-BuTX; AChR-positive endplates were counted in 10 fields from each animal using ImageJ software. (G). Sections were stained for C3b/ iC3b (H) and C9/MAC (I) and staining quantified as above. Tissue sections from isotype control (J) or $2 \mathrm{H} 2(\mathbf{K})$ treated animals were double-stained for AChR together with anti-C3b/iC3b (top panel) or C9/MAC (bottom panel) and imaged on a Zeiss confocal microscope. The scale bar shown is $10 \mu \mathrm{m}$; all images were captured at identical magnification. Statistical significance was obtained by unpaired t-test and $\mathrm{P}<0.05$ was considered significant; significant differences and $\mathrm{p}$ values, mean and SD are shown in the figures.
\end{abstract}

C7 has been neglected as a therapeutic target, in contrast to C5 where numerous Pharma companies are developing blocking $\mathrm{mAb}$ or other drugs.

To identify clones secreting blocking anti-C7 mAbs early in clone screening we used a high-throughput hemolysis assay; notably, C7-blocking $\mathrm{mAb}$ were rare events, only 7 inhibitory clones identified from 15,000 screened clones over 15 separate fusions. Although we did not test for non-blocking anti-C7 mAbs in all fusions, this was done in early fusions and C7-binding activity was detected in $\sim 5 \%$ of clones screened. This contrasts markedly with our experience with C5 where $\sim 10 \%$ of the anti-C5 $\mathrm{mAb}$ generated were strong function blockers (17). The $\mathrm{mAb}$ described here bound C7 in ELISA (Figure 2A) and inhibited lysis of ShEA in CP assays (Figure 1) with mAb 17E7 and 59E7 being the most efficient for human serum; these $\mathrm{mAb}$ gave similar inhibition profiles to the currently available therapeutic anti-C5 $\mathrm{mAb}$ eculizumab and crovalimab. The $\mathrm{mAb}$ were generated in $\mathrm{C} 7-$ deficient mice and several showed strong cross-species activity. The $\mathrm{mAb} 2 \mathrm{H} 2$ was most effective for rat serum and 73D1 for mouse serum; mAb 3B11 efficiently inhibited both human and rat serum (Table 1). Inhibition by $17 \mathrm{E} 7$ and $2 \mathrm{H} 2$ was confirmed in a modified CP assay using near-physiological serum concentrations. The in vitro inhibition data was confirmed in vivo for the mouse C7-blocking mAb 73D1, and for the human C7-specific mAb 17E7, the latter tested in C7-deficient mice administered human C7. Mouse serum inhibition by 73D1 was equivalent to the antiC5 blocker BB5.1 (Figure 4A), widely used in animal models (19) and catalyzing the enthusiasm for anti-C5 therapeutics; the efficient inhibition of mouse complement by mAb 73D1 make it a valuable tool for animal studies targeting MAC specifically without interfering with $\mathrm{C} 5$ a generation.

Both of the human C7-specific mAbs, 17E7 and 59E7, showed strong and stable binding to human C7 in SPR $(\mathrm{KD}=1.02 \times$ $10^{-9}, 9.31 \times 10^{-10}$, respectively; Table 2). Strong binding of $\mathrm{mAb}$ $73 \mathrm{D} 1$ to mouse $\mathrm{C7}$ was also confirmed by SPR analysis $(\mathrm{KD}=$ $2.31 \times 10^{-9}$, Table 2). Epitope specificity was tested in ELISA; surprisingly, all of the antibodies reactive with a given species C7 gave no signal when used as a pair in sandwich ELISA, showing that they bound the same or overlapping epitopes on C7 (Figure 2B). All the mAb worked as detect or capture in sandwich ELISA in conjunction with a polyclonal anti-C7, demonstrating that all bound C7 in this context. These observations suggest that there is a dominant epitope or surface of the $\mathrm{C} 7$ molecule that is critical for function and the target for all selected $\mathrm{mAb}$. We plan structural studies to identify this epitope as we recently described for the anti-C5 mAb BB5.1 (19).

The mAb $2 \mathrm{H} 2$ stood out from the other mAb generated; this rat-selective $\mathrm{mAb}$ was a highly efficient complement inhibitor in vitro inhibiting at a dose at least 10-fold lower than the other inhouse blocking $\mathrm{mAb}$; at this dose, $\mathrm{C} 7$ is in $\sim 10$-fold molar excess compared to the mAb. Although $2 \mathrm{H} 2$ recognized $\mathrm{C} 7$ protein immobilized on plastic in direct ELISA, when tested in SPR immobilized on the chip surface, this mAb did not capture either human or rat $\mathrm{C} 7$ flowed over the surface. In vivo, this $\mathrm{mAb}$ completely blocked serum lytic activity at a quarter of the dose routinely used in rodent models $(10 \mathrm{mg} / \mathrm{kg}$ versus $40 \mathrm{mg} / \mathrm{kg}$ body weight) for other terminal pathway inhibitory $\mathrm{mAb}$, including BB5.1, the in-house anti-rat C5 4G2, and the 73D1 anti-C7 mAb $(18,19)$. When administered at the standard dose, $2 \mathrm{H} 2$ effectively blocked complement for at least seven days in rats, compared to $48 \mathrm{~h}$ for the other $\mathrm{mAb}$ at the same dose. Rats treated with the lowest dose of $\mathrm{mAb} 2 \mathrm{H} 2$ showed complete loss of hemolytic activity and were protected from disease compared to controls in the EAMG model; treated rats did not lose weight or develop paralysis, endplates were protected from damage and MAC deposition at endplates was markedly reduced (Figures 4D-K).

Taken together, the above data demonstrating that $\mathrm{mAb} 2 \mathrm{H} 2$ binds denatured but not native $\mathrm{C} 7$ and blocks hemolytic activity in vitro and in vivo at much lower concentrations than other blocking $\mathrm{mAb}$ and when $\mathrm{C} 7$ is in molar excess, suggested that $2 \mathrm{H} 2$ has a different mechanism of action to the other blocking $\mathrm{mAb}$. We reasoned that it might inhibit by binding the transient 
C5b-7 complex. To test this, we used reactive lysis assays; all the blocking $\mathrm{mAb}$, including $2 \mathrm{H} 2$, inhibited lysis when added to C5b6-bearing cells prior to addition of $\mathrm{C} 7$, indicating that they either prevented binding of $\mathrm{C} 7$ to $\mathrm{C} 5 \mathrm{~b} 6$ or its unfolding to reveal $\mathrm{C} 8$-binding sites. When the blocking $\mathrm{mAb}$ were added to preformed C5b-7 cells, only $2 \mathrm{H} 2$ inhibited suggesting that it additionally bound to $\mathrm{C} 5 \mathrm{~b}-7$ and blocked $\mathrm{C} 8$ binding (Figures $\mathbf{1 G}, \mathbf{H})$. It was not possible to test directly the impact of $2 \mathrm{H} 2$ on the fluid-phase C5b-7 complex in these assays because of the transience of C5b-7 membrane-binding activity; instead, we explored binding of $2 \mathrm{H} 2$ and the other blocking $\mathrm{mAb}$ to forming and formed TCC in the fluid phase. Pull-downs from rat serum activated in the presence of mAb $2 \mathrm{H} 2$ included all terminal pathway proteins $\mathrm{C} 5 \mathrm{~b}-\mathrm{C}$, demonstrating that the $\mathrm{mAb}$ captures intermediates in the fluid phase while permitting binding of later components to generate a mAb-TCC complex (Figures 3F, G). The anti-human $\mathrm{C7} \mathrm{mAb}$ 17E7, 59E7, and $73 \mathrm{D} 1$, when incubated in human serum during activation as above, each pulled down all the TCC components demonstrating that they too bound C7 in the complex and did not interfere with fluid-phase TCC generation (Figures $3 \mathbf{H}-\mathbf{J}$ ). Binding of the novel mAbs to pre-formed TCC was confirmed by sandwich ELISA capturing the complex on the aE11 anti-C9 neo-specific antibody (Figures 2C, D).

In some respects, the mechanism of action of $\mathrm{mAb} 2 \mathrm{H} 2$ resembles that of the naturally occurring MAC inhibitor clusterin; this fluid phase regulator binds C5b-7, preventing membrane attachment and insertion of the complex, but allows recruitment of C8 and C9 to form the TCC (32-34). Clusterin is a weak inhibitor of hemolysis that "buffers" bystander effects. The Streptococcal inhibitor of complement (SIC) protein similarly binds fluid-phase intermediates (predominantly C5b-7) and blocks the capacity of the complex to associate with membranes $(35,36)$. In contrast to $2 \mathrm{H} 2$, neither clusterin nor SIC caused inhibition in reactive lysis when C5b-7 was already on the target surface, confirming that they only interfere with membrane binding of nascent C5b-7. The capacity of $2 \mathrm{H} 2$ to bind and inhibit membrane-bound C5b-7 complexes suggests a dual impact on C5b-9 assembly; these properties make $\mathrm{mAb} 2 \mathrm{H} 2$ a powerful MAC inhibitor, a "super-clusterin" working with much greater efficiency to inhibit MAC assembly and resultant lysis.

In summary, we have demonstrated that, with regard to blocking hemolytic activity in vivo and in vitro, targeting MAC downstream of $\mathrm{C} 5$ is at least as effective as targeting C5. We describe anti-C7 $\mathrm{mAbs}$ that are powerful blockers of human, primate, rat and mouse $\mathrm{C} 7$, several working across species. We describe one $\mathrm{mAb}, 2 \mathrm{H} 2$, that shows selectivity for the C5b-7 complex and inhibits at greatly reduced dose compared to component-specific mAbs; although this $\mathrm{mAb}$ is predominantly active in rat, it is proof of principle that complex-specific mAb can be generated. These have potentially great advantages over current anti-complement drugs in terms of dose, frequency of administration and infection risk; they have the potential to open up new therapeutic fields for anti-complement drugs with significantly lower cost of treatment and more suited to treatment of common, chronic diseases. Current efforts are focused on the development of $2 \mathrm{H} 2$-like mAb that bind and block the human C5b-7 complex.

\section{DATA AVAILABILITY STATEMENT}

The raw data supporting the conclusions of this article will be made available by the authors, without undue reservation.

\section{ETHICS STATEMENT}

The animal study was reviewed and approved by UK Home Office; license numbers: PF4167C0A and P8159A562.

\section{AUTHOR CONTRIBUTIONS}

WZ performed all the laboratory analyses and wrote the first draft of the manuscript. BPM conceived and planned the study and oversaw the data handling and manuscript preparation. All authors contributed to the article and approved the submitted version.

\section{FUNDING}

WZ was supported by a PhD Studentship from the Life Sciences Research Network Wales (LSRN), LSRN Translational Support Fund, and by a Consolidator Award supported by Wellcome Trust ISSF funding to Cardiff University. BPM is supported by the UK Dementia Research Institute Cardiff.

\section{ACKNOWLEDGMENTS}

We thank Prof. David Kanavagh for providing eculizumab and Roche Diagnostics for donating crovalimab. We acknowledge Michelle Somerville for assistance with the Zeiss confocal microscope.

\section{SUPPLEMENTARY MATERIAL}

The Supplementary Material for this article can be found online at: https://www.frontiersin.org/articles/10.3389/fimmu.2020. 612402/full\#supplementary-material

SUPPLEMENTARY FIGURE 1 | Binding sensorgrams of the novel mAbs to $\mathrm{C7}$ protein. mAb 3B11 (lgM) was immobilized on a protein $L$ Series $S$ sensor chip (GE Healthcare \#29-2051-38) and mAb 73D1 (IgG2a, $\kappa$ ) immobilized on a mouse lgG capture sensor chip (GE Healthcare, \# BR-1008-38) at approximately 60 RU. Human, rat or mouse $\mathrm{C} 7$ was flowed in HEPES-buffered saline (HBS) in a dilution range of 66 to $4 \mathrm{nM}$ (3B11) or 66 to $8 \mathrm{nM}$ (73D1) and interactions with the immobilized mAbs were analyzed. Sensorgrams were collected and KDs calculated using the Langmuir 1: 1 binding model with RI values set to zero. Sensorgrams are shown with raw data in colored lines and fitted data in dotted lines (average of 3); all binding data and analyses are included in Table 2 . The SPR analysis was performed in an automated manner using T200 Biacore Evaluation Software version 2 (GE Healthcare). 


\section{REFERENCES}

1. Zelek WM, Xie L, Morgan BP, Harris CL. Compendium of current complement therapeutics. Mol Immunol (2019) 114:341-52. doi: 10.1016/ j.molimm.2019.07.030

2. Harris CL, Pouw RB, Kavanagh D, Sun R, Ricklin D. Developments in anticomplement therapy; from disease to clinical trial. Mol Immunol (2018) 102:89-119. doi: 10.1016/j.molimm.2018.06.008

3. Morgan BP, Harris CL. Complement, a target for therapy in inflammatory and degenerative diseases. Nat Rev Drug Discov (2015) 14:857-77. doi: $10.1038 / \mathrm{nrd} 4657$

4. Rother RP, Rollins SA, Mojcik CF, Brodsky RA, Bell L. Discovery and development of the complement inhibitor eculizumab for the treatment of paroxysmal nocturnal hemoglobinuria. Nat Biotechnol (2007) 25:1256-64. doi: $10.1038 /$ nbt1344

5. Hillmen P, Young NS, Schubert J, Brodsky RA, Socié G, Muus P, et al. The complement inhibitor eculizumab in paroxysmal nocturnal hemoglobinuria. N Engl J Med (2006) 355:1233-43. doi: 10.1056/NEJMoa061648

6. Röth A, Nishimura JI, Nagy Z, Gaàl-Weisinger J, Panse J, Yoon SS, et al. The complement C5 inhibitor crovalimab in paroxysmal nocturnal hemoglobinuria. Blood (2020) 135:912-20. doi: 10.1182/blood.2019003399

7. McKeage K. Ravulizumab: First Global Approval. Drugs (2019) 79:347-52. doi: 10.1007/s40265-019-01068-2

8. Cashman SM, Ramo K, Kumar-Singh R. A non membrane-targeted human soluble CD59 attenuates choroidal neovascularization in a model of age related macular degeneration. PloS One (2011) 6:19078. doi: 10.1371/ journal.pone.0019078

9. Rollins SA, Matis LA, Springhorn JP, Setter E, Wolff DW. Monoclonal antibodies directed against human C5 and C8 block complement-mediated damage of xenogeneic cells and organs. Transplantation (1995) 60:1284-92. doi: 10.1097/00007890-199512000-00017

10. Rinder CS, Rinder HM, Smith MJ, Tracey JB, Fitch J, Li L, et al. Selective blockade of membrane attack complex formation during simulated extracorporeal circulation inhibits platelet but not leukocyte activation. J Thorac Cardiovasc Surg (1999) 118:460-6. doi: 10.1016/S0022-5223(99)70183-2

11. Biesecker G, Gomez CM. Inhibition of acute passive transfer experimental autoimmune myasthenia gravis with Fab antibody to complement C6. J Immunol (1989) 142(8):2654-9.

12. Lin K, Zhang L, Kong M, Yang M, Chen Y, Poptic E, et al. Development of an anti-human complement C6 monoclonal antibody that inhibits the assembly of membrane attack complexes. Blood Adv (2020) 4:2049-57. doi: 10.1182/ bloodadvances. 2020001690

13. Köhler G, Milstein C. Continuous cultures of fused cells secreting antibody of predefined specificity. Nature (1975) 256:495-7. doi: 10.1038/256495a0

14. Zelek WM, Harris CL, Morgan BP. Extracting the barbs from complement assays: Identification and optim of a safe substitute for traditional buffers. Immunobiology (2018) 223:744-9. doi: 10.1016/j.imbio.2018.07.016

15. Morgan BP. Complement Methods and Protocols. Totowa, New Jersey: Humana Press (2000). doi: 10.1385/159259056x

16. Chamberlain-Banoub J, Neal JW, Mizuno M, Harris CL, Morgan BP. Complement membrane attack is required for endplate damage and clinical disease in passive experimental myasthenia gravis in Lewis rats. Clin Exp Immunol (2006) 146:278-86. doi: 10.1111/j.1365-2249.2006.03198.x

17. Morgan BP, Chamberlain-Banoub J, Neal JW, Song W, Mizuno M, Harris CL. The membrane attack pathway of complement drives pathology in passively induced experimental autoimmune myasthenia gravis in mice. Clin Exp Immunol (2006) 146:294-302. doi: 10.1111/j.1365-2249.2006.03205.x

18. Zelek WM, Taylor PR, Morgan BP. Development and characterization of novel anti-C5 monoclonal antibodies capable of inhibiting complement in multiple species. Immunology (2019) 157:283-95. doi: 10.1111/imm.13083

19. Zelek WM, Menzies GE, Brancale A, Stockinger B, Morgan BP. Characterizing the original anti-C5 function-blocking antibody, BB5.1, for species specificity, mode of action and interactions with C5. Immunology (2020) 161:103-13. doi: $10.1111 /$ imm. 13228

20. Pickering RJ. Significance of abnormalities of serum complement in human disease. Postgrad Med (1968) 43:39-43. doi: 10.1080/00325481.1968.11693275

21. Schur PH, Austen KF. Complement in human disease. Annu Rev Med (1968) 19:1-24. doi: 10.1146/annurev.me.19.020168.000245
22. Nesargikar P, Spiller B, Chavez R. The complement system: History, pathways, cascade and inhibitors. Eur J Microbiol Immunol (2012) 2:10311. doi: 10.1556/eujmi.2.2012.2.2

23. Sim RB, Schwaeble W, Fujita T. Complement research in the 18th-21st centuries: Progress comes with new technology. Immunobiology (2016) 221:1037-45. doi: 10.1016/j.imbio.2016.06.011

24. Zelek WM, Fathalla D, Morgan A, Touchard S, Loveless S, Tallantyre E, et al. Cerebrospinal fluid complement system biomarkers in demyelinating disease. Mult Scler J (2019) 1352458519887905:1-9. doi: 10.1177/ 1352458519887905

25. Carpanini SM, Torvell M, Morgan BP. Therapeutic inhibition of the complement system in diseases of the central nervous system. Front Immunol (2019) 10:1-17. doi: 10.3389/fimmu.2019.00362

26. Clark SJ, Bishop PN. The eye as a complement dysregulation hotspot. Semin Immunopathol (2018) 40:65-74. doi: 10.1007/s00281-017-0649-6

27. Zelek WM, Stott M, Walters D, Harris CL, Morgan BP. Characterizing a pHswitch anti-C5 antibody as a tool for human and mouse complement C5 purification and cross-species inhibition of classical and reactive lysis. Immunology (2018) 155:396-403. doi: 10.1111/imm.12982

28. Harder MJ, Höchsmann B, Dopler A, Anliker M, Weinstock C, Skerra A, et al. Different levels of incomplete terminal pathway inhibition by eculizumab and the clinical response of PNH patients. Front Immunol (2019) 10:1-7. doi: 10.3389/fimmu.2019.01639

29. Hill A, Piatek CI, Peffault de Latour R, Wong LL, Wells RA, Brodsky RA, et al Breakthrough Hemolysis in Adult Patients with Paroxysmal Nocturnal Hemoglobinuria Treated with Ravulizumab: Results of a 52-Week Extension from Two Phase 3 Studies. Blood (2019) 134:952-2. doi: 10.1182/ blood-2019-128929

30. Würzner R, Joysey VC, Lachmann PJ. Complement component C7. Assessment of in vivo synthesis after liver transplantation reveals that hepatocytes do not synthesize the majority of human C7. J Immunol (1994) 152(9):4624-9.

31. Wurzner R, Platonov AE, Beloborodov VB, Pereverzev AI, Vershinina IV, Fernie BA, Orren A, et al. How partial C7 deficiency with chronic and recurrent bacterial infections can mimic total $\mathrm{C} 7$ deficiency: temporary restoration of host C7 levels following plasma transfusion. Immunology (1996) 88:407-11. doi: 10.1046/j.1365-2567.1996.d01-663.x

32. Nam-Ho C, Toshio M, Motowo T. A serum protein SP40,40 modulates the formation of membrane attack complex of complement on erythrocytes. $\mathrm{Mol}$ Immunol (1989) 26:835-40. doi: 10.1016/0161-5890(89)90139-9

33. Jenne DE, Tschopp J. Molecular structure and functional characterization of a human complement cytolysis inhibitor found in blood and seminal plasma: Identity to sulfated glycoprotein 2, a constituent of rat testis fluid. Proc Natl Acad Sci U S A (1989) 86:7123-7. doi: 10.1073/pnas.86.18.7123

34. Hallström T, Uhde M, Singh B, Skerka C, Riesbeck K, Zipfel PF. Pseudomonas aeruginosa uses Dihydrolipoamide dehydrogenase (Lpd) to bind to the human terminal pathway regulators vitronectin and clusterin to inhibit terminal pathway complement attack. PloS One (2015) 10:1-21. doi: 10.1371/journal.pone.0137630

35. Hadders MA, Bubeck D, Roversi P, Hakobyan S, Forneris F, Morgan BP, et al. Assembly and Regulation of the Membrane Attack Complex Based on Structures of C5b6 and sC5b9. Cell Rep (2012) 1:200-7. doi: 10.1016/ j.celrep.2012.02.003

36. Fernie-King BA, Seilly DJ, Willers C, Würzner R, Davies A, Lachmann PJ. Streptococcal inhibitor of complement (SIC) inhibits the membrane attack complex by preventing uptake of C567 onto cell membranes. Immunology (2001) 103:390-8. doi: 10.1046/j.1365-2567.2001.01249.x

Conflict of Interest: BPM has provided advice on complement to Roche and is a consultant to RaPharma. The authors are named inventors on a patent (PCT/ EP2020/073430) describing the anti-C7 mAbs.

Copyright (c) 2020 Zelek and Morgan. This is an open-access article distributed under the terms of the Creative Commons Attribution License (CC BY). The use, distribution or reproduction in other forums is permitted, provided the original author(s) and the copyright owner(s) are credited and that the original publication in this journal is cited, in accordance with accepted academic practice. No use, distribution or reproduction is permitted which does not comply with these terms. 